\title{
Estrategias educativas para padres utilizadas en la educación inicial en बुత్ర niños de 1 a 3 años
}

Sandra Arely Oliva Jaimez

\section{RESUMEN}

Con la siguiente investigación se pretende estimular las diferentes áreas de desarrollo de los niños a partir de estrategias educativas en la familia. A través de la aplicación de las estrategias se llegó a la conclusión de que el desarrollo y la personalidad de los niños, depende en gran medida del contexto que los rodea, por ello es importante brindarle un ambiente que lo estimule.

\section{ABSTRACT}

The following investigation tries to stimulate the different development areas of the kids, from educative strategies. From the application of the strategies, it was possible to conclude that the development and personality of the children depends on the context that surrounds them, so it is important to offer them a stimulating atmosphere.

\section{Introducción هes}

La educación consiste en brindar las herramientas necesarias para mejorar las actitudes y facultades del hombre con la finalidad de formar personas equilibradas, que puedan integrarse a una sociedad de manera más fácil. Es por ello que la educación inicial se ha convertido en una necesidad social.

Ofrecer a los niños desde sus primeros años las herramientas que le permitan mejorar su forma de ver el mundo, así como su percepción de sí mismos les ayudará a dirigir su camino y asegurar su estancia dentro de la sociedad.

\section{Planteamiento del problema:}

Un problema que se presenta con frecuencia en esta sociedad es que el niño muestra dificultad para integrase a la sociedad pues en ella existen reglas muy distintas a las de casa. Esta investigación pretende dar solución a este problema por medio de estrategias que, le faciliten al niño su acceso a la sociedad.

\section{Objetivo:}

El objetivo principal que esta investigación persigue es brindar a los padres estrategias educativas para estimular las áreas de desarrollo de los niños de 1 a 3 años. La finalidad de ofrecer las estrategias a padres es mejorar la calidad de vida tanto del niño como de los padres. Cabe mencionar que las propuestas están diseñadas desde un enfoque pedagógico y para el ámbito familiar porque es el lugar donde el niño inicia la construcción de su personalidad, así como la percepción de su mundo.

\section{Justificación:}

Esta investigación pretende beneficiar a las familias, en especial orientar a los padres y hacerlos conscientes de su responsabilidad y el cargo de educadores que tienen.

Además de mejorar las capacidades del niño con la finalidad de que se desarrolle integralmente. Para ello se han diseñado una serie de actividades que estimulen sus áreas de desarrollo

\section{Antecedentes:}

Las estrategias fueron creadas con base a teorías de desarrollo de niños de 1 a 3 años, como son las teorías cognitivas de Piaget quien describe la etapa sensoriomotriz y preoperacional en niños de 1 a 3 años; la Psicosocial de Erikson que describe la etapa de confianza frente a desconfianza, y autonomía frente a vergüenza en niños de esta edad; y la psicosexual de Freud en la que explica las etapas oral y anal por las que pasa el niño.

\section{Estructura:}

En el primer capítulo se describirá lo que es la educación inicial y su importancia, en el segundo capítulo se explicará todo el 


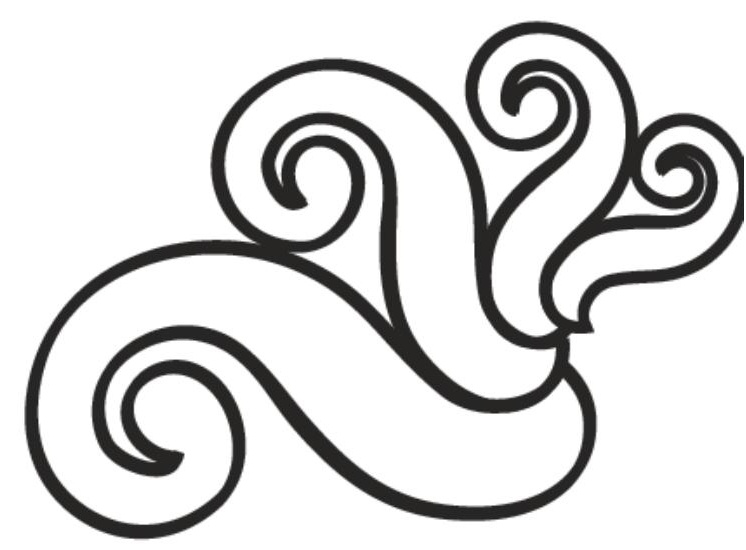

desarrollo físico, psicosocial, psicomotriz y cognitivo del niño, en el tercero se darán a conocer las estrategias educativas, sus ventajas e importancia, en el cuarto capítulo se describirá la metodología empleada durante la investigación y finalmente en el quinto capítulo se darán a conocer los resultados y conclusiones de este trabajo.

\section{Marco Teóriconea}

\section{Capítulo I Educación Inicial}

En este primer capítulo se describirá el concepto de educación inicial, los objetivos que persigue y la importancia que tiene en la vida del niño y en el ambiente familiar.

\section{I.1 Concepto de educación.}

Según el diccionario de ciencias de la educación (Abad, Amaro, Anaya, Asensi, 1997) La palabra educación proviene del vocablo latín educare que significa conducir, guiar u orientar.

Según García Hoz (en Abad, et al. 2005) la finalidad de la educación es brindar al individuo las herramientas necesarias para el perfeccionamiento de las facultades específicamente humanas; por lo tanto la educación consiste en la conducción de las personas hacia un comportamiento final dado a través de la formación de actitudes.

\section{I.1.1 ¿Qué es la educación inicial?}

El programa de educación inicial de la $\mathrm{S}$ E P (Casas de la Torre, Esquivel, Licona y Uribe 1997) menciona que la educación inicial consiste en el logro de una progresiva maduración de las facultades infantiles con la finalidad de formar equilibradamente al niño.

I.1.2 Importancia y objetivos de la educación inicial
La educación inicial tiene un papel importante en la vida del niño pues facilita o limita el desarrollo. Los niños desde pequeños construyen patrones de comportamiento, sistemas de explicaciones y principios morales que guían sus juicios respecto al mundo. Crecen y maduran en un mundo de interacciones; a través de ellas configuran, se reconocen y estructuran sus capacidades.

Los niños interactúan con el mundo con el propósito de buscar, experimentar, constatar y estructurar principios y acciones que aseguren su ingreso y permanencia en el núcleo social.

La educación inicial se ha convertido en una necesidad social ya que a través de ésta, el niño favorece su proceso de formación y la estructuración de su personalidad. Los niños se forman dentro de un grupo social. La protección y desarrollo dentro de éste dependerá de su formación y personalidad.

Los objetivos de la educación inicial establecidos por el programa de la S E P (Casas de la Torre et al. 1997) son los siguientes:

- Promover el desarrollo personal del niño a través de oportunidades que le permitan ampliar y mejorar su lenguaje, psicomotricidad y afectividad.

- Estimular al niño para que participe en actividades, en las que desarrolle su capacidad de socializar.

- Enriquecer las prácticas de cuidados y atención a los niños por parte de los padres.

- Proporcionar al niño actividades en las que aplique y desarrolle su proceso cognitivo.

- Estimular la adquisición y dominio del lenguaje.

- Ejercitar el control y manejo de movimientos del cuerpo.

- Proporcionar al niño elementos, para conocer a los seres vivos y la importancia de cuidar la naturaleza y nuestra comunidad.

Dar las bases que sustenten la educación de los niños desde sus primeros años, es una tarea 


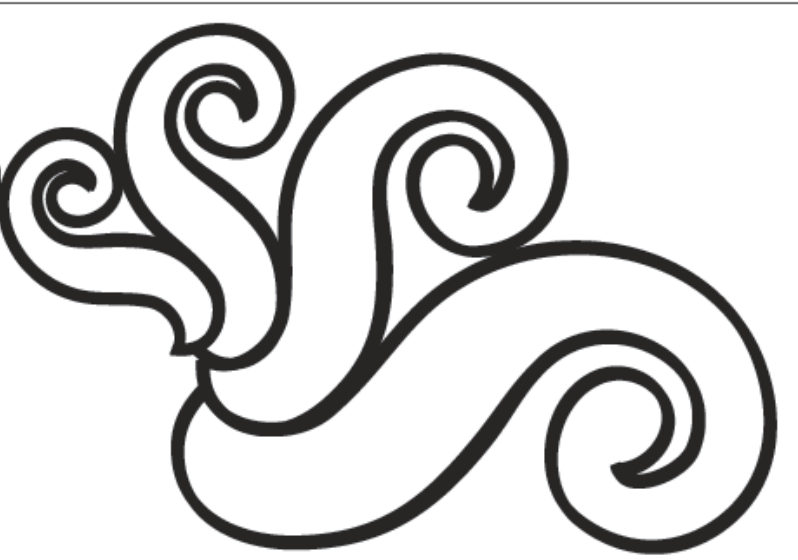

importante para los padres. Es por eso que surgen programas de educación inicial que sirven como apoyo a los padres para guiar a sus hijos.

\section{Capítulo II}

\section{Desarrollo de los niños de 1 a 3 años}

En este segundo capítulo se plantearán todas las teorías sobre el desarrollo de niños de 1 a 3 años. Se explicará cada área de desarrollo; física, cognitiva, psicosocial, psicomotriz y de leguaje. Se citarán algunos autores de gran importancia: Piaget, Freud, Erikson y Vigotsky.

\section{II.1 Desarrollo físico}

El desarrollo físico de los niños de 1 a 3 años de edad se lleva a cabo rápidamente, aunque de manera más lenta que en la lactancia. El niño de esta edad es más delgado en comparación como era antes de este período.

A continuación se presenta una tabla de peso y talla de niño y niñas de 1 a 3 años de edad (http://www.crecerjuntos.com.ar/tablas. htm).

\begin{tabular}{|c|c|c|c|c|}
\hline \multirow[b]{2}{*}{ Edad } & \multicolumn{3}{|c|}{ Niñas } & \multirow{2}{*}{$\begin{array}{l}\text { Niños } \\
\text { peso }(\mathrm{kg})\end{array}$} \\
\hline & talla $(\mathrm{cm})$ & peso $(\mathrm{kg})$ & talla $(\mathrm{cm})$ & \\
\hline 12 Meses & 74,3 & 9,53 & 76,1 & 10,15 \\
\hline 15 meses & 77,5 & 10,40 & 79,0 & 10,70 \\
\hline 18 meses & 80,9 & 10,8 & 82,4 & 11,4 \\
\hline 21 meses & 83,3 & 11,70 & 84,8 & $12,0 \mathrm{C}$ \\
\hline 24 meses & 86,50 & 11,90 & 87,6 & 12,50 \\
\hline $21 / 2$ años & 91,30 & 12,90 & 92,3 & 13,67 \\
\hline 3 años & 95,6 & 13,90 & 96,5 & 14,6 \\
\hline
\end{tabular}

Durante esta etapa el niño aprende a caminar, adquiere el lenguaje, aprende a controlar sus esfínteres y se convierte en una persona egocéntrica es por eso que ésta etapa es muy difícil y significativa para su vida.

\section{II.1.2 Nutrición}

Para un óptimo crecimiento del niño es importante que la alimentación que lleva sea nutritiva. La mayoría de los alimentos no poseen las vitaminas necesarias para el desarrollo y crecimiento del niño, por tal motivo los especialistas recomiendan alguna vitamina $A, C, D$ y hierro para complementar su nutrición.

Es importante que se le proporcione alimentos ricos en calcio, tales como leche, queso, yogurt, verduras, leguminosas, tortillas de maíz y sardinas. La vitamina $D$ y los rayos del sol ayudan a calcificar los huesos.

El desayuno es conocido como la comida más importante del día por esto es necesario que sea balanceado y proporcione los nutrientes adecuados para el crecimiento y salud del niño. Investigaciones realizadas (Calderón, Sánchez, Suárez, 2003) demuestran que los niños que no desayunan se ven afectados en algunas áreas cognoscitivas tales como la habilidad de recordar y utilizar información recién adquirida, la fluidez verbal y el control de la atención.

La hora de la comida es uno de los momentos de convivencia y acercamiento entre los integrantes de la familia, por eso es recomendable que se realice por lo menos una comida al día con toda la familia.

También es recomendable dar la comida al bebé sin prisa, sin nervios y no desesperarse, molestarse o pelearse en caso de que el niño no quiera comer. Es normal que los niños entre 18 y 24 meses de edad pasen por periodos largos en los que disminuya su apetito, esta situación suele preocupar a los padres pues pareciera que no comen nada. Por otro lado, no comen la misma cantidad que los adultos y no todos necesitan la misma cantidad de comida para desarrollarse con toda normalidad.

Es importante que no se les obligue, que se les de la oportunidad de descubrir lo que desean 


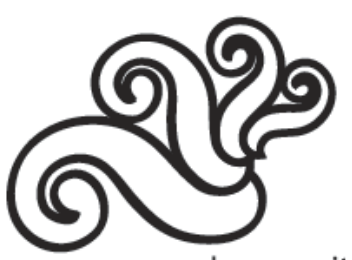

comer, que se les permita escoger el momento de alimentarse y si prefieren hacerlo con cuchara o tenedor.

Hay que tener en cuenta que el uso habitual de premios, castigos y amenazas con el fin de conseguir que coman no son recomendables, ya que afectan la relación entre madre e hijo e incluso se puede malacostumbrar el niño.

Puede creerse o considerarse que los niños gordos son más sanos, sin saber que la mayoría de estos niños están sobrealimentados y por ello más propensos a tener dificultades digestivas y a enfermar de cualquier cosa. Además les cuesta más trabajo moverse, y por lo tanto es más frecuente que sean más lentos en aprender a caminar.

\section{II.1.3 Control de esfínteres}

El control de esfínteres es uno de los momentos más importantes durante esta etapa pues representa un paso importante para la autonomía del niño. Lamentablemente para algunos padres es difícil detectar cuándo es el momento adecuado para iniciar con su entrenamiento.

El momento oportuno para comenzar depende del desarrollo fisiológico y psicológico del niño. Algunos bebes entre los 18 y 24 meses ya tienen los medios adecuados para controlar sus esfínteres.

La edad de inicio en el control de esfínteres también puede variar de acuerdo al grado de estimulación y convencimiento que la madre ejerce sobre el pequeño, el medio ambiente que le rodea y las presiones a su alrededor.

Algunas señales que el niño presenta para detectar el momento adecuado e iniciar la enseñanza son las siguientes:

- Algunos niños avisan cuando se sienten incómodos con su pañal y piden que los cambien.

- Se mantienen secos mínimo durante dos horas al día o después de dormir.
- Expresan mediante gestos o palabras que están a punto de orinar

En el proceso de educación para el inicio de control de esfínteres interviene el desarrollo físico adecuado, un ambiente familiar adecuado y un entorno social en general que facilite un evento tan natural como éste.

\section{II.1.3.1 Etapa de desarrollo psicosexual sexual según Freud}

Freud fue un médico vienés que desarrolló el Psicoanálisis (en Papalia, 2005, p.37) -un enfoque terapéutico que considera que el desarrollo es moldeado por fuerzas inconscientes que motivan la conducta humana.

Freud propuso que la personalidad se forma en la niñez mientras los niños se enfrentan a conflictos inconscientes entre impulsos innatos y las exigencias de la vida civilizada.

En cada etapa del desarrollo psicosexual existen zonas placer, ya sea: la boca, el ano y los genitales.

La primera etapa de desarrollo psicosexual es la oral (en Papalia et al. 2005, p.39), que se presenta en el niño de los 12 a los 18 meses. La zona erógena está en la boca y los labios; por lo tanto, cualquier actividad orientada a la boca le produce placer, por ejemplo, la succión y la alimentación.

Freud describe también que (en Papalia et al. 2005, p.39) la segunda etapa de desarrollo es la anal, ésta se presenta en niños de 18 meses a tres años. La zona erógena es la región anal; por lo tanto, actividades como retención y expulsión de heces producen placer en el niño. El entrenamiento de control de esfínteres es una actividad importante.

Para Freud las tres primeras etapas: oral, anal, y el complejo edípico, son cruciales. Sugirió que si los niños reciben muy poca o demasiada gratificación están en riesgo de una fijación, una detención en el desarrollo que puede 
mostrarse en la personalidad adulta. Por ejemplo, los niños que durante la etapa oral no fueron satisfechos en sus necesidades, al crecer pueden morderse las uñas, convertirse en fumadores o desarrollar habilidades mordaces. Un niño que tuvo un entrenamiento de control de esfínteres demasiado estricto puede fijarse en la etapa anal; al crecer puede tener una personalidad estreñida, ser obsesivo en cuanto a la limpieza y pulcritud, rígidamente atado a programas y rutinas, o por el contrario ser demasiado desordenado.

\section{II.1.4 Desarrollo cognitivo}

Sabemos que el niño además de tener un desarrollo físico también tiene un desarrollo cognitivo que determinará su personalidad y conducta.

El desarrollo cognitivo de un niño dependerá de la acción directa del infante con el ambiente que lo rodeé, así como de los aspectos heredados.

Así mismo el niño tendrá que pasar por un proceso de aprendizaje, el cual no siempre se presenta al mismo ritmo o de la misma forma.

\section{II.1.4.1 La mecánica básica del aprendizaje desde el enfoque conductista.}

Papalia, Olds y Feldman (2005) definen al condicionamiento clásico como un mecanismo de aprendizaje en el cual una persona aprende a dar una respuesta refleja o involuntaria ante un estímulo. Este tipo de aprendizaje es extinguido si no se refuerza.

Un ejemplo de este condicionamiento clásico es la succión, donde el estímulo es el pezón y la respuesta es la succión.

El condicionamiento operante es un mecanismo de aprendizaje basado en el reforzamiento, en el cual el aprendiz actúa sobre el ambiente e influye en él. Por ejemplo, el bebé que ríe para obtener la atención de sus padres.

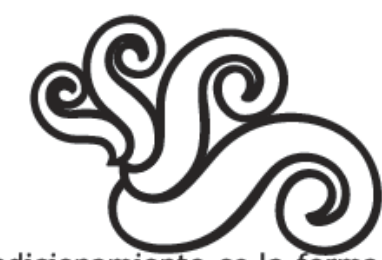

A esta edad el condicionamiento es la forma más común en la que los niños aprenden sobre lo que está a su alrededor.

Es la forma más habitual aunque algunas veces no resulte ser la mejor; un ejemplo puede ser la mamá que utiliza un estimulo como un dulce para que el niño coma. La mayoría de las veces los niños se malacostumbran.

Calderón, Sánchez y Suárez (2003) señalan que algunos investigadores sugieren que los procesos de la memoria de un bebé son muy parecidos a los de niños mayores o adultos, salvo que su tiempo de retención es más breve. Esos estudios han encontrado que los bebés repetirán una acción días o semanas, siempre que se les recuerde la situación en que la aprendieron.

\section{II.1.4.2 Etapas cognitivas de Jean Piaget}

Existen etapas cognitivas cuyo autor es el teórico suizo Jean Piaget, él consideraba que el desarrollo cognitivo era producto de los esfuerzos del niño para entender y actuar en su mundo. Estas etapas se basan en los procesos de pensamiento y en las conductas que refleja este proceso.

\section{II.1.4.2.1 Etapa sensoriomotora}

Esta etapa abarca desde el nacimiento hasta los dos años de edad. Durante ella los bebés aprenden acerca de ellos mismos y de su mundo mediante su actividad sensorial y motora en desarrollo. Los bebés pasan de ser criaturas que responden principalmente a partir de reflejos y conducta aleatoria, a ser niños orientados hacia metas.

Piaget (Papalia, et al. 2005, p.135) indica que dentro de la etapa sensoriomotora se pueden encontrar seis subetapas:

Durante las primeras cinco subetapas los bebés aprenden a coordinar la entrada de sus sentidos y a organizar sus actividades en relación con el ambiente. Durante la sexta y 


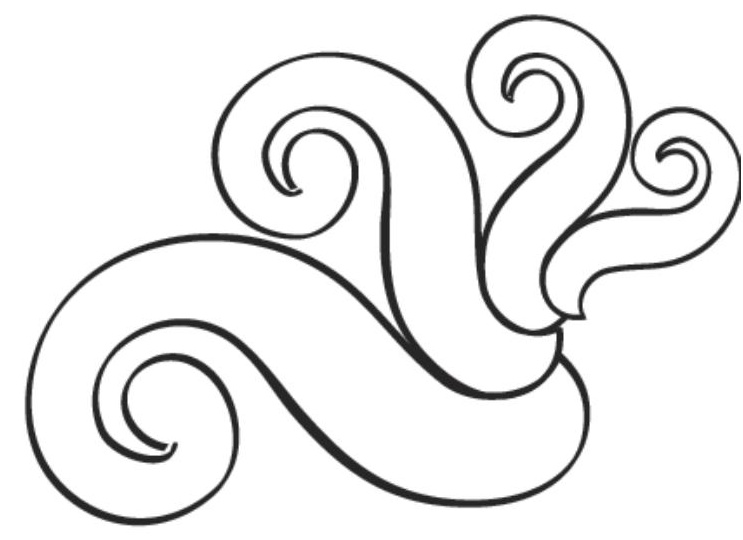

última subetapa progresan del aprendizaje por ensayo y error al uso de símbolos y conceptos para resolver problemas sencillos.

1. Uso de reflejos: esta primer subetapa abarca desde el nacimiento hasta el mes. Los bebés ejercitan sus reflejos innatos y ejercen cierto control sobre ellos. No coordinan la información de sus sentidos. No sujetan el objeto que están viendo.

2. Reacciones circulares primarias: ésta abarca desde el primer al cuarto mes. El bebé reproduce conductas placenteras que al principio ocurren por azar (como la succión del pulgar). Las actividades se centran en el cuerpo del bebé más que en los efectos de la conducta sobre el ambiente. Los bebés hacen las primeras adaptaciones adquiridas; es decir, succionan distintos objetos de manera diferente. Empiezan a coordinar la información sensorial y a sujetar objetos.

3. Reacciones circulares secundarias: de los cuatro a los ocho meses de edad se desarrolla esta etapa. Los bebés muestran mayor interés por el ambiente; repiten acciones que producen resultados interesantes (como agitar un sonajero) y prolongan experiencias. Las acciones son intencionales pero inicialmente no son dirigidas hacia metas.

4. Coordinación de esquemas secundarios: de los ocho a los doce meses. La conducta es más deliberada y propositiva (intencional) a medida que coordinan los esquemas aprendidos con anterioridad como mirar y sujetar un sonajero, y usan conductas previamente aprendidas para alcanzar las metas (como gatear por la habitación para obtener un juguete). Pueden anticipar los eventos.

5. Reacciones circulares terciarias: abarca desde los doce hasta los dieciocho meses. Los niños muestran curiosidad y experimentan; varían a propósito de sus acciones para ver los resultados. Exploran activamente sumundo para determinar que hay un nuevo objeto, evento o situación. Intentan nuevas actividades, usan ensayo y error para resolver problemas.
6. Combinaciones mentales: abarca de los 18 a los 24 meses de edad. En esta etapa los niños pueden hacer una representación mental de los objetos, ya no están limitados al ensayo y error. El pensamiento simbólico les permite pensar en eventos $y$ anticipar sus consecuencias sin recurrir siempre a la acción.

\section{II.1.4.2 Etapa Preoperacional.}

Jean Piaget denominó a la niñez temprana, de los 2 a los 7 años de edad, la etapa preoperacional porque los niños todavía no están listos para realizar operaciones o manipulaciones mentales que requieren del pensamiento lógico. El desarrollo característico en esta segunda etapa importante para el desarrollo cognitivo es una gran expansión en el uso del pensamiento simbólico o habilidad de representación, el cual empieza a emerger al final de la etapa sensoriomotora.

Los procesos en el pensamiento simbólico son acompañados por una comprensión creciente del espacio, casualidad, identidades, categorización, y numero. Contar con símbolos para las cosas ayuda a los niños a recordar y pensar en ellas sin tenerlas físicamente presentes.

Piaget (Papalia, et al. 2005, p.136) describe la etapa preoperacional con los siguientes parámetros:

1. Uso de símbolos: Los niños ya no necesitan estar en contacto sensoriomotor con un objeto, persona o evento para pensar en él. Los niños pueden imaginar que los objetos o la gente tienen propiedades distintas a las que realmente tienen.

2. Comprensión de las identidades: Los niños se percatan de que las

alteraciones superficiales no cambian la naturaleza de las cosas.

3. Comprensión de causa y efecto: los niños se dan cuenta de que los eventos tienen causas y efectos.

4. Habilidad para clasificar: Los niños organizan objetos, personas y eventos en 


\section{II.1.5.1 Percepción}

calidad significativa.

5. Comprensión del número: los niños pueden contar y manejar cantidades.

6. Empatía: se tornan más capaces de imaginar cómo pueden sentirse los demás.

7. Noción del intelecto: Los niños se percatan de su actividad mental y del funcionamiento de su mente.

Las limitaciones que se presentan en el pensamiento preoperacional son las siguientes:

1. Concentración: Incapacidad para descentrar. Los niños se concentran en un aspecto de la situación y descuidan los restantes.

2. Irreversibilidad: No entienden que algunas operaciones $o$ acciones pueden ser revertidas reestableciendo la situación original

3. Énfasis en los estados más que en las trasformaciones: Los niños no entienden el significado de la transformación entre estados.

4. Razonamiento transductivo: No usan el razonamiento deductivo o inductivo; en lugar de ellos saltan de un aspecto particular a otro y ven causas donde no existen

5. Egocentrismo: Los niños asumen que todos piensan, perciben, sienten igual que ellos.

6. Animismo: Los niños atribuyen la vida a los objetos que no la tienen

Incapacidad para distinguir la apariencia de la realidad: Los niños confunden lo que es real con la apariencia exterior.

\section{II.1.5 Desarrollo psicomotor}

Johanne Durivage (2000) describe que la psicomotricidad estudia la relación entre los movimientos y las funciones mentales, indaga la importancia del movimiento en la formación de la personalidad y el aprendizaje, y se ocupa de las perturbaciones del proceso para establecer medidas educativas.

Algunos aspectos generales de la Psicomotricidad son los siguientes:

Es una manera de tomar conciencia del medio ambiente, existe una parte innata porque el niño percibe sensaciones desde los primeros meses de su vida, y otra aprendida porque el niño se desarrolla según las estimulaciones que recibe del exterior.

La percepción sensoriomotriz es el conjunto de estimulaciones visuales, auditivas y táctiles. Johanne Durivage (2000) indica que los tipos de percepción son los siguientes:

1. La percepción visual: se desarrolla a partir de ejercicios de coordinación óculo-motriz, de percepción figura-fondo, repercepción de la posición, de las relaciones espaciales y de discriminación de formas y de memoria.

2. La percepción táctil: se desarrolla a partir de la conciencia del cuerpo y del desarrollo de la presión. Por ejemplo el niño con los ojos cerrados, toca un objeto y puede describir si es redondo, duro, de vidrio, etc.

3. La percepción auditiva: Se desarrolla a partir de ejercicios de concentración, memoria, discriminación auditiva. Por ejemplo el niño, con los ojos cerrados puede distinguir entre el sonido de un gato y un perro.

4. Es a partir de la percepción que el niño aprende del medio ambiente que lo rodea, por tal motivo, ésta juega un papel muy importante en su desarrollo.

\section{II.1.5.2 Motricidad}

El desarrollo motor se refleja a través de la capacidad de movimiento. Johanne Durivage (2000) clasifica a la motricidad en 5 tipos de acuerdo a su desarrollo espontáneo:

1. Los movimientos locomotores, o automatismos: son movimientos gruesos y elementales que ponen en función al cuerpo como totalidad. Por ejemplo, caminar, gatear, arrastrarse, etc.

2. La coordinación dinámica: es la capacidad 


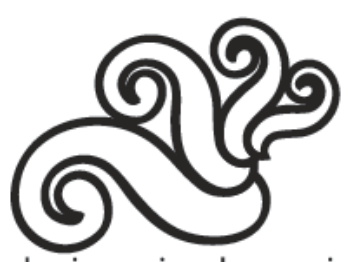

de sincronizar los movimientos de diferentes partes del cuerpo. Por ejemplo, brincar.

3. La disociación: es la posibilidad de mover voluntariamente una o más partes del cuerpo mientras que las otras permanecen inmóviles o ejecutan un movimiento diferente. Por ejemplo, caminar sosteniendo un vaso con agua.

4. La coordinación visiomotriz: consiste en la acción de las manos u otra parte del cuerpo realizada en coordinación con los ojos. Por ejemplo, botar una pelota con la mano.

5. La motricidad fina: consiste en la posibilidad de manipular objetos con toda la mano o con movimientos más diferenciados utilizando los dedos. Por ejemplo, tomar un lápiz.

\section{II.1.5.3 Esquema corporal}

El esquema corporal es el concepto que el niño tiene de su cuerpo y de sí mismo. El conocimiento de sí mismo es el fruto de todas las experiencias activas o pasivas que tiene el niño, por lo tanto, es indispensable para la elaboración de la personalidad. Es importante que el niño identifique su cuerpo ya que es un medio por el cual se expresará y establecerá contacto con los demás. Algunos de los siguientes ejercicios permiten el desarrollo del esquema corporal, el cual se divide en 5 áreas (Durivage 2000):

1. La imitación: es la reproducción de gestos, movimientos o posiciones.

2. Exploración: es la familiarización con nuevos objetos. El niño busca varias posibilidades de manipulación al investigar un objeto libremente. Por ejemplo jugar con cajas de cartón.

3. Nociones corporales: palabras que designan partes del cuerpo. Por ejemplo: señalar una parte del cuerpo que la madre o maestro mencionan.

4. Utilización: es la aplicación de la exploración. El niño adapta y organiza las partes descubiertas.

5. Creación: inventar e imaginar situaciones, personas, objetos a través del cuerpo corporal o con objetos.

\section{II.1.5.4 Elaboración de la lateralidad}

Es el resultado de la predominancia motriz del cerebro. La predominancia se presenta sobre los segmentos corporales derecho e izquierdo, tanto en el nivel de los ojos como en el de las manos y pies.

Para facilitar la orientación del cuerpo se establece este proceso:

1. Diferenciación global. Su propósito es utilizar los dos lados del cuerpo, afirmar el eje corporal, disociar progresivamente cada lado y facilitar la preferencia natural que se expresa por la habilidad creciente de uno de ellos, por ejemplo: hacer avión con los dos brazos extendidos.

2. Orientación del propio cuerpo. Se refiere a las nociones derecha- izquierda. En esta etapa interviene la toma de conciencia de los dos lados, apoyada por la verbalización. La orientación se refuerza con los ejercicios de disociación. Por ejemplo los niños hacen que se peinan, que se lavan los dientes, etc.

3. Orientación corporal orientada. Es la elaboración de la lateralidad sobre otra persona u objeto. Ejemplo tocar el pie derecho de la maestra.

Los problemas en este desarrollo tienen consecuencias en la vida cotidiana del niño y repercuten en el aprendizaje escolar, especialmente en la lectura y escritura.

\section{II.1.5.5 Elaboración del espacio}

La construcción del espacio se hace paralelamente a la elaboración del esquema corporal, y ambos dependen de la evolución de los movimientos, es decir de las capacidades motrices del niño que inician desde su nacimiento.

El espacio se vive según las aferencias táctiles, auditivas y visuales. A partir de la experiencia los espacios aislados se juntan y aparece un cierto sentido de la dimensión. Durivage 
(2000, p.28) propone los siguientes ejercicios de elaboración de espacio:

1. Adaptación espacial: corresponde a la etapa de espacio vivido. El cuerpo se desplaza de acuerdo a los espacios. Por ejemplo, pasar debajo de una silla.

2. Nociones espaciales: palabras que designan el espacio, refuerzan todos los pasos.

3. Orientación espacial: se desarrolla a partir de ejercicios de orientación espacial, de agrupaciones y de reproducción de trayectos. Por ejemplo, ir solo a la tienda o a lugares de la casa.

4. Estructuración espacial: consiste en la organización del espacio sin referirse precisamente al cuerpo. Así se forman las nociones de distancia, volumen y estructuración espacio-temporal. Ejemplo, dar dos pasos chicos o dos pasos grandes.

5. Espacio gráfico: es el intermediario entre el espacio de la acción concreta y el espacio mental.

\section{II.1.5.6 Elaboración del tiempo y ritmo}

Esta noción se elabora a través del movimiento que, por su automatización, introduce a un cierto orden temporal debido a la contracción muscular. Durivage (2000, p.29) sugiere el desarrollo de las siguientes áreas para su elaboración:

1. La regulación. Por la experiencia del cuerpo los movimientos se afinan y de la repetición resulta un carácter rítmico.

2. Adaptación a un ritmo. La capacidad de adaptar un movimiento al ritmo se logra primeramente en el nivel de las manos y posteriormente los movimientos locomotores. Ejemplo, correr y aplaudir rítmicamente.

3. Repetición de un ritmo. Favorece la interiorización de los ritmos.

4. Nociones temporales. La designación del tiempo y el ritmo. Ejemplo, correr rápido como un conejo, caminar lento como una tortuga.

5. Orientación temporal. La capacidad de situarse en una relación de tiempo y actuar corporalmente en consecuencia a un antes o a un después.

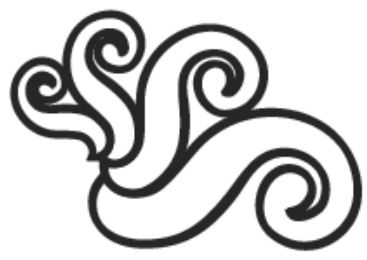

6. Estructuración temporal. Implica la conciencia de los movimientos y de sus desplazamientos ejecutados en cierto tiempo y en cierta distancia. Por ejemplo, cruzar una habitación en el tiempo que dura una melodía.

\section{III.1.6 Desarrollo psicosocial}

Se han desarrollado teorías acerca de las crisis que vive el niño en cada etapa de su vida. El desarrollo psicosocial de 1 a 3 años presenta dos etapa, la primera es confianza frente a desconfianza y la segunda, autonomía frente vergüenza.

La primera etapa de desarrollo psicosocial que Erikson identificó es la de confianza básica frente a la desconfianza básica.

Esta etapa comienza al nacer y continúa aproximadamente hasta los 12 ó 18 meses; los bebés desarrollan un sentido de confianza con las personas y objetos de su mundo. $\mathrm{Si}$ la confianza predomina, como debería, los niños desarrollan la virtud de la esperanza: la creencia de que pueden satisfacer sus necesidades y cumplir sus deseos. Si predomina la desconfianza los niños verán al mundo como un lugar hostil e impredecible y tendrán problemas para formar relaciones.

El elemento crucial en el desarrollo de la confianza es el cuidado sensible, afectuoso y consciente. Erikson consideró que la situación de alimentación es el escenario para establecer la mezcla correcta de confianza y desconfianza. Erikson (en Papalia, et al. 2005) refiere que los apegos tienen valor adaptativo para los bebés, asegurando que sus necesidades psicológicas y físicas serán satisfechas. El niño debe tener un equilibrio entre la tendencia negativa y la positiva, en este caso la gente necesita confiar en el mundo y sus habitantes, pero también aprender cierta desconfianza para protegerse del peligro.

La segunda etapa de desarrollo psicosocial es la de autonomía frente a la vergüenza. Esta 


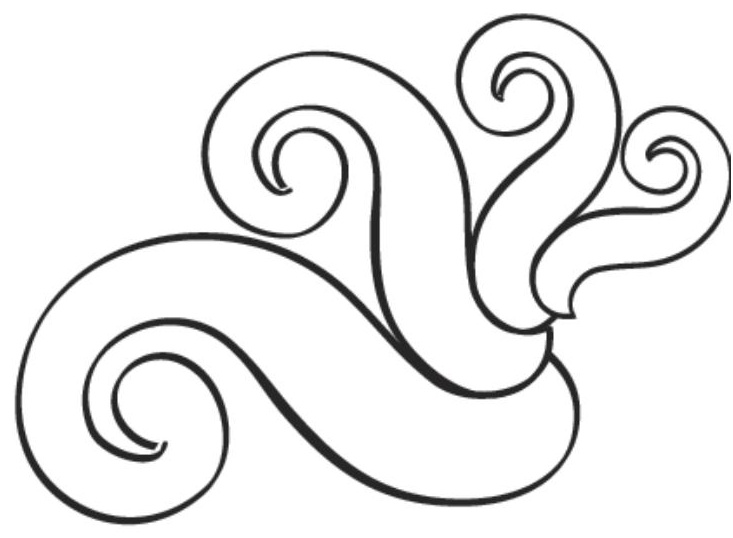

se presenta entre los 18 meses y los tres años de edad; el niño desarrolla un equilibrio de independencia y autosuficiencia sobre la vergüenza y la duda, el cual es marcado por un cambio del control externo al autocontrol.

La virtud que emerge durante esta etapa es la voluntad. El entrenamiento para el control de esfínteres es un paso importante hacia la autonomía y el autocontrol. También lo es el lenguaje a medida que los niños son más capaces de hacer que sus deseos sean entendidos.

\section{II.1.6.1 Formación axiológica del niño.}

Como parte de su desarrollo integral la formación de valores en el niño es muy importante. El niño empieza la formación de su personalidad desde el hogar, en la familia. Es por eso que los padres tienen la responsabilidad de fomentar valores en sus hijos.

La importancia y finalidad de fomentar valores en los hijos es mejorar su calidad de vida, la percepción del mundo que los rodea y de sí mismos.

Algunos de los valores que se deben enseñar a los hijos son los siguientes: cooperación, libertad, felicidad, honestidad, humildad, amor, paz, respeto, responsabilidad, sencillez, tolerancia y unidad.

Es importante también enseñarles a valorar y cuidar la naturaleza. La realización de actividades en las cuales los niños aprenden a cuidar su medio ambiente, son importantes en su educación ecológica; actividades como las siguientes:

- Cuidar el agua.

- Tirar la basura en el bote.

- Conocer y enseñar los cuidados que deben tener los animales.

- Regar y plantar árboles, flores y plantas.

\section{II.1.7 Desarrollo del lenguaje}

El niño de1 a 3 años presenta varios cambios y avances en el leguaje, comienza por emitir sonidos como el llanto, el arrullo, el balbuceo, la imitación accidental, es decir, sonidos sin la comprensión del significado.

Para pasar a la etapa lingüística en la que ya emite palabras mal pronunciadas pero con un significado.

El crecimiento del lenguaje ilustra la forma en la que interactúan todos los aspectos del desarrollo. Los bebés por lo general emiten sus primeras palabras al final del primer año.

\section{II.1.7.1 Habilidades del lenguaje}

Conforme pasa el tiempo el niño va desarrollando y perfeccionando más su lenguaje. Algunas de las habilidades que desarrolla según Papalia, et al. (2005) son las siguientes:

- $\quad 10$ a 18 meses dice palabras sueltas.

- 18 meses. Entiende la función simbólica de mencionar los nombres y usa gestos más elaborados.

- 14 meses, usa gestos simbólicos.

- 16 a 24 meses, aprende muchas palabras nuevas, ampliando rápidamente su vocabulario que aumenta de 50 palabras a más de 400; usa verbos y adjetivos.

- $\quad 18$ a 24 meses, dice la primera oración (dos palabras).

- 20 meses, usa menos gestos; dice los nombres de más cosas.

- 20 a 22 meses, tiene un crecimiento acelerado de la comprensión.

- 24 meses, usa muchas frases de dos palabras; ya no balbucea; desea hablar.

- 30 meses, aprende nuevas palabras, casi cada día; habla en combinaciones de tres palabras o más; entiende muy bien, comete errores gramaticales.

- 36 meses, dice más palabras, tiene algunos errores de sintaxis.

\section{II.1.7.2 Teoría de Vygotsky}

El desarrollo del lenguaje del niño depende de la interacción con las personas que lo rodean y de la estimulación que se le brinde.

Uno de los autores que se dedicaron al estudio 


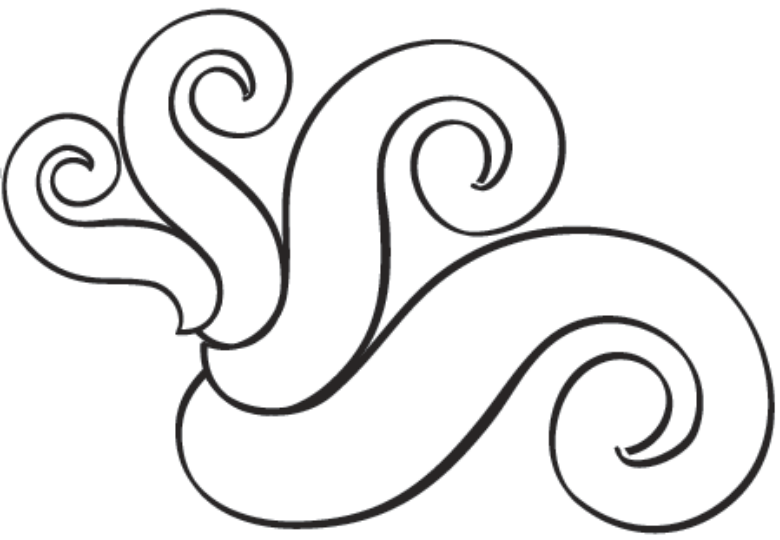

de los niños y la influencia que tiene el medio en su desarrollo fue Vygotsky. El psicólogo ruso Lev Semenovich Vygotsky defendió siempre la perspectiva contextual, en particular a la aplicación del desarrollo cognitivo de los niños. El énfasis central de Vygotsky es el complejo social, cultural e histórico del cual es parte el niño. La teoría sociocultural que enfatiza la participación activa del niño con su medio ambiente, él afirmaba que los niños aprenden a través de la interacción social; Papalia, et al. (2005, p.146) señala que los niños adquieren habilidades cognitivas como parte de su inducción a una forma de vida. Las actividades compartidas ayudan al niño a interiorizar las formas de pensamiento $y$ conductas de su sociedad y a apropiarse de ellas.

Para Vygotsky (Papalia, et al. 2005) los adultos ayudan a dirigir y organizar el aprendizaje del niño antes de que éste pueda dominarlo e interiorizarlo. El término que utiliza es el de andamiaje que es el apoyo temporal que los padres, maestros $u$ otros proporcionan a un niño para hacer una tarea hasta que puede hacerla por sí solo.

\section{II.1.7.3 Influencia del medio para el desarrollo del leguaje.}

La obtención del lenguaje, como cualquier otro aprendizaje, se basa en la experiencia.

El niño aprende a hablar con base a una serie de reforzamientos como elogios, sonrisas y atención, que los adultos le brindan en el momento en que emite un sonido, eso provoca que repita esos sonidos reforzándolos.

Por tal motivo los padres juegan un papel importante en el aprendizaje del lenguaje de los niños.

Otro de los factores que influyen en el desarrollo del niño es la estimulación que recibe del medio que lo rodea, ya sea de los hermanos que todo el tiempo juegan y hablan con él, o por la convivencia con niños de sus edad en alguna institución como una guardería o escuela materna, donde tendrá la necesidad de comunicarse con personas extrañas a él. Así como ejercicios de estimulación que los motiven a hablar o emitir distintos sonidos.

Para poder crear estrategias educativas que favorezcan la vida del niño y su familia, es indispensable antes estudiar y analizar todas las causas que provoquen su comportamiento, así como sus etapas de desarrollo.

\section{Capítulo III Estrategias educativas a padres}

En este tercer capítulo se definirá lo que es una estrategia educativa, su importancia y ventajas en la vida del niño. Finalmente se plantearán las estrategias creadas para mejorar cada área de desarrollo del niño, tales como: cognitiva, psicosocial, física, lingüística y psicomotriz.

\section{III.1 ¿Qué es una estrategia?}

Van Cube (1981) define la estrategia como el conjunto de acciones coordinadas y efectivas dirigidas a lograr un objetivo determinado.

\section{III.1.1 Importancia de aplicar estrategias a temprana edad}

Aplicar las estrategias en una edad temprana es de suma importancia, ya que durante estos años el niño se encuentra en un proceso de formación y desarrollo de su personalidad.

El niño durante la edad temprana pasa por un proceso de estructuración, reconocimiento y configuración de sus capacidades, que le permitirán crear explicaciones y concepciones respecto al mundo que lo rodea.

Al aplicar las estrategias educativas durante esta etapa, estamos brindando al niño las herramientas necesarias para optimizar su desarrollo personal y sus capacidades 


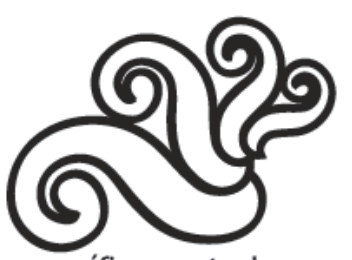

específicamente humanas con la finalidad de mejorar su calidad de vida.

\section{III.1.2 Ventajas de la aplicación de estrategias educativas en edad temprana}

La intervención temprana es un proceso sistemático de planeación y suministro de servicios terapéuticos y educativos a las familias que necesitan ayuda para satisfacer las necesidades de desarrollo de los bebés, niños pequeños y preescolares.

La intervención temprana es efectiva si:

1. Empieza temprano y se continúa a lo largo de los años preescolares

2. Son intensivas

3. Proporcionan experiencias educativas directas, no sólo del entrenamiento de los padres

4. Adoptan un enfoque comprensivo, incluyendo la salud, consejo familiar y servicios familiares

5. Están adaptadas a diferencias y necesidades individuales

El programa de educación inicial impartido por la SEP, Abad et al. (1997) expone las siguientes ventajas de la intervención temprana en los niños:

- Resulta más fácil a padres la educación de sus hijos.

- Existe un desarrollo personal del niño.

- El niño tiene la oportunidad de mejorar su lenguaje y adquirirlo con mayor facilidad.

- Se desarrolla la Psicomotricidad del niño.

- El niño se convierte en una persona más sociable.

- Es más atendido y cuidado por sus padres.

- Se establece un vínculo padre e hijo mas cercano.

- Se desarrolla la confianza y autonomía del niño.

- El niño desarrolla la autoestima y seguridad en sí mismo.

- Mejora la calidad de vida de padres e hijos.

- Existen menos posibilidades de conflictos en el niño y la familia.
III.1.3 La importancia de la intervención de los padres en la aplicación de estrategias.

Los padres son las personas más importantes en la vida del niño, con ellos han compartido su vida desde el momento de nacer. Son los padres los que hasta esta etapa se han encargado de sus cuidados y necesidades, y gracias a ellos él ha sido capaz de interactuar con el medio y confiar en él. Por tal motivo, los padres juegan un papel importante en la intervención temprana, además de ser ellos los encargados de aplicar las estrategias diariamente, a través de esa relación afectiva, con la cual se logran con mayor facilidad los objetivos.

\section{III.1.4 Estrategias para estimular las áreas de desarrollo del niño de 1 a 3 años.}

El proyecto preescolar de Harvard (Papalia, et al. 2005) sugiere las siguientes directrices para promover el desarrollo cognitivo de bebés y niños pequeños:

1. En los primeros meses, proporcionar estimulación sensorial, pero evitar la estimulación excesiva y los ruidos distractores.

2. A medida que los bebés crecen, crear un ambiente que propicie el aprendizaje, que incluya libros, juguetes interesantes $y$ un lugar para jugar.

3. Responder a las señales del bebé. Esto establece un sentido de confianza en que el mundo es un lugar amistoso y da a los bebés un sentido de control sobre su vida.

4. Dar a los bebés el poder para efectuar cambios a través de juguetes que pueden ser sacudidos, moldeados o movidos.

5. Proporcionar a los bebés libertad para explorar. No se les debe confinar regularmente durante el día en la cuna.

6. Hablar con los bebés. Ellos no aprenden el lenguaje escuchando radio o televisión.

7. Cuando hable o juegue con los bebés, referirse a lo que están interesados en 
el momento, en lugar de que se trate de reorientar su atención hacia otra cosa.

8. Disponer de oportunidades para aprender habilidades básicas como comparar y clasificar objetos.

9. Aplaudir las nuevas habilidades y ayudar a los bebés a practicarlas y expandirlas.

10. Leer a los bebés en una atmósfera cálida e interesada para una edad temprana. La lectura en voz alta y hablar de las historias desarrollan las habilidades cognitivas.

11. Utilizar el castigo con moderación. No ridiculizar los resultados de la exploración normal de ensayo y error.

\section{III.1.5.1Estrategias para mejorar el desarrollo} físico de su hijo.

Es bueno asistir al pediatra, para hacer un chequeo general del niño por lo menos cada dos meses.

Es importante dar al niño alimentos que lo nutran no sólo que lo engorden o que lo llenen.

Hay que tener en cuenta que el uso habitual de premios, castigos y amenazas con el fin de conseguir que coma no son recomendables, ya que afectan la relación entre madre e hijo e incluso se puede malacostumbrar el niño.

Recomendaciones para el control de esfínteres.

¿Como lograr el proceso de una forma más fácil?

- Es muy importante lograr que el proceso de control de esfínteres sea algo natural, no obligado, hacer que el niño vea a otras personas hacer uso del sanitario, familiarizarse con el inodoro u orinal (nica o escusado) que va a utilizar, para que no le genere angustia.

- Es conveniente que estas actividades se den bajo un ambiente agradable, sin la participación de castigos, obligar o ridiculizar a los niños no contribuye a alcanzar la meta deseada.

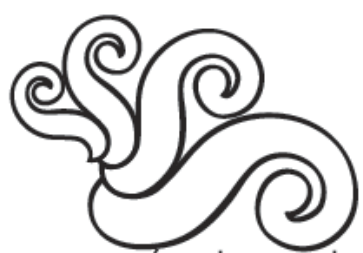

- Se debe utilizar ropa cómoda que le facilite al pequeño despojarse de la misma cuando sienta el deseo de orinar o evacuar, el calzón entrenador puede ser de utilidad, la ropa complicada o apretada puede obstaculizar las maniobras cuando el niño tiene la urgencia

- Favorecer un horario es una medida que auxilia el hábito, esto es, si conocemos el patrón de evacuaciones de un niño y sabemos que suele defecar dos o tres veces al día, se le puede invitar a usar el baño u orinal a esas horas, para tratar de irlo acostumbrando al uso.

- Tratar de conocer las señales que un niño manifiesta cuando quiere orinar.

- Es de vital importancia evitar las conductas hostiles y agresivas.

\section{III.1.5.2 Estrategias para mejorar el desarrollo cognitivo del niño.}

El desarrollo cognitivo del niño depende de distintos factores como son la herencia y la experiencia, el ambiente familiar, la interacción entre padres e hijos, el número de libros en el hogar, la presencia de juguetes que fomenten el desarrollo de conceptos, la participación de los padres en el juego con los niños y la estimulación del aprendizaje. En algunos casos la posición socioeconómica también tiene influencia, ya que la capacidad de los padres para proporcionar recursos educativos es menor y frena el crecimiento cognitivo del niño. La atención que los padres brinden a sus hijos también influye en el desarrollo del niño.

Es importante tener en cuenta estos factores, pues podrían ayudarnos a mejorar o frenar el desarrollo cognitivo del niño.

Los niños de 1 a 18 meses se encuentran en una etapa llamada sensoriomotora en la que se están conociendo a ellos mismos y al mundo que les rodea. En esta etapa es necesario que al niño se le presenten situaciones en las que 


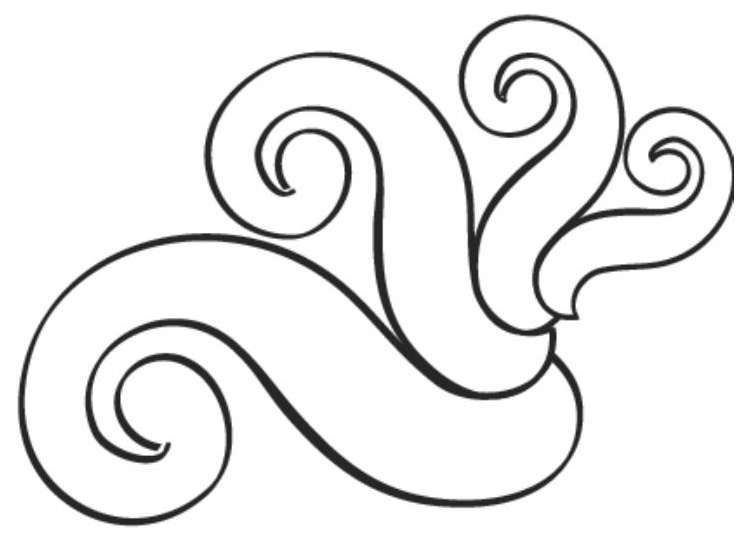

haga uso de todos sus sentidos con la finalidad de desarrollarlos. Por ejemplo: presentarle distintos olores, sabores, texturas, sonidos, etc.

De los 2 a los 7 años se encuentran en otra etapa intelectual llamada preoperacional, en la que el niño ya es capaz de resolver problemas, pero únicamente si los puede ver; durante esta etapa es importante dejar que resuelva el problema que se le presente por sí sólo, y brindarle ayuda en caso de que sea un problema muy difícil. Por ejemplo: el niño quiere un dulce que está en la mesa, para alcanzarlo necesita subir una silla, subir a la mesa y tomar el dulce. Aunque le costará trabajo hay que dejar que lo haga solo.

Durante esta etapa el juego tiene un papel importante en el aprendizaje, por eso es recomendable mostrar al niño juegos y materiales que desarrollen su habilidad cognitiva, como son: rompecabezas, cajas, recipientes, juegos de construcción, objetos de distintos colores y tamaños, carros, barcos, muñecos como animales o personas, objetos que giren al moverlos, objetos de acción que al jalar o golpear produzcan sonido, libros, cuentos, etc.

Materiales para introducirlos a las actividades artísticas como: papel, cartulina, papel de colores, texturas distintas, crayones gruesos, masillas, plastilinas, pintura digital, pinturas de agua, plumones, lápices de colores, etc.

\section{III.1.5.3 Estrategias para mejorar el desarrollo Psicosocial del niño.}

El desarrollo Psicosocial del niño abarca la parte emocional, que también interviene en la formación de su personalidad. Esta área se divide en dos etapas, la primera que abarca desde el nacimiento hasta los 18 meses, consiste en desarrollar un sentido de confianza en el niño, a partir de cuidados sensibles, afectuosos y conscientes. El momento ideal para hacerlo es durante la alimentación.

Es importante desarrollar el sentido de confianza en el niño, de no ser así podría volverse inseguro o tener problemas para relacionarse.

La segunda etapa consiste en desarrollar la autonomía del niño, abarca de los 18 meses a los 3 años de edad, es recomendable que realice y resuelva problemas por sí sólo y en caso de que no los llegue a lograr, tratar de no avergonzarlo porque esto podría frenar su iniciativa para hacer las cosas. Por ejemplo: si está aprendiendo a ir al baño, y tuvo un accidente, es importante tratar de no avergonzarlo o regañarlo pues, tal vez no quiera continuar el entrenamiento.

Se encuentra en una etapa egocéntrica en la cual quiere toda la atención, tiene dificultad para compartir y esperar, hace berrinches frecuentemente. Es importante establecer límites y reglas claras, hacerle entender que no conseguirá nada a través de berrinches y ayudarlo a reconocer qué es de su propiedad y qué es para compartir.

Es recomendable también:

- Tratar de que conviva más con niños de su edad, en especial si es hijo único o vive solo con adultos.

- Establecer límites y reglas. Ser firme en las advertencias y consecuencias.

- Tratar de no castigar, los niños comprenden mejor una explicación.

- Dar oportunidad de elegir entre distintas opciones. Es importante para su autonomía.

- Apoyar a los niños en cada momento para que hagan las cosa por sí solos. Como comer, tomar agua o ir solos al baño.

\section{III.1.5.4 Estrategias para mejorar el desarrollo del lenguaje del niño.}

El desarrollo de lenguaje del niño, dependerá de la estimulación que reciba de su entorno. Para desarrollar y perfeccionar el lenguaje del niño se pueden tomar en cuenta las siguientes estrategias: 


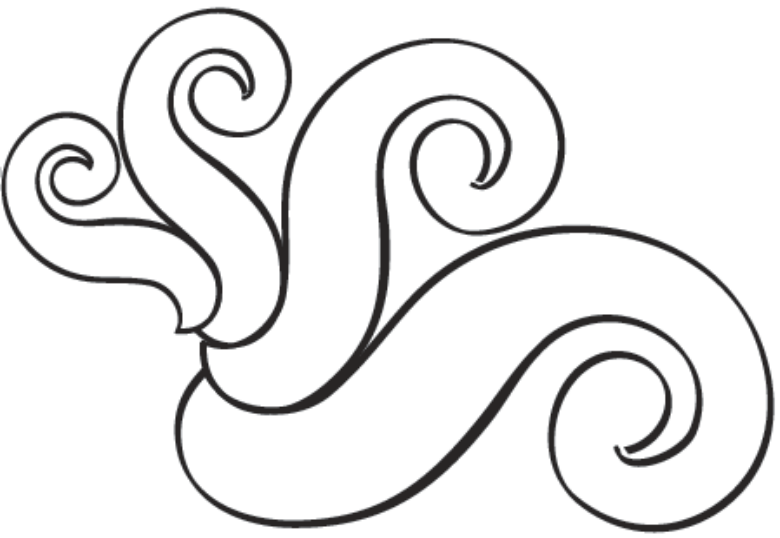

- Repetir palabras para que el niño las imite.

- Nombrar el objeto antes de dárselo.

- Responder a señas.

- Demostrar que cuando pide con palabras obtiene respuesta.

- Corregir palabras.

- Describir objetos y situaciones.

- Conversar con él sobre lo que sucede en ese momento.

- Darle instrucciones.

- Hacerle preguntas.

- Leerle cuentos, rimas y preguntar sobre lo que trató el cuento.

- Cantarle.

- Prestarle atención.

- No utilizar diminutivos.

- Llamar a las cosas por su nombre.

\section{III.1.5.5 Estrategias para mejorar el desarrollo psicomotriz del niño.}

El desarrollo del movimiento del niño influye también en la formación de la personalidad y el aprendizaje. La psicomotricidad es la relación entre los movimientos y las funciones mentales (Durivage, J 2000, p. 18).

La Psicomotricidad se caracteriza por los siguientes aspectos:

- La percepción, es la forma en la que el niño conoce y aprende del mundo que lo rodea. Desarrollar los 5 sentidos ayudará al niño a percibir y aprender de una mejor manera. Para mejorar la percepción se pueden realizar ejercicios o presentar situaciones que le permitan al niño utilizar todos los sentidos. Por ejemplo distintas texturas para el tacto, olores para el gusto, colores y formas para la vista, sabores para el gusto y distintos sonidos para el oído.

- La motricidad es otro aspecto que hay que desarrollar: la motricidad gruesa que son movimientos como caminar, gatear, correr, saltar etc., y la motricidad fina que son movimientos con la mano como escribir. La capacidad de coordinar alguna parte del cuerpo con los ojos. Para desarrollar esta área es necesario que el niño realice ejercicios en los que pueda, subir, bajar, trepar, deslizarse, brincar, gatear, arrastrarse, ocupar las manos como escribiendo, dibujando, etc.

- Esquema corporal es el concepto que el niño tiene sobre su cuerpo. Para ayudar al niño a conocerse un poco más se pueden hacer ejercicios, juegos o canciones que indiquen las partes de su cuerpo.

- La lateralidad es la noción sobre derechoe izquierdo. Ejercicios que pueden ayudar al niño son juegos o canciones que indiquen los lados.

- Elaboración del espacio es la noción que el niño tiene del espacio en el que se encuentra; puede realizar ejercicios que le ayuden a comprender el espacio como ir a lugares conocidos: la tienda, el baño, la cocina etc.

\section{Capítulo IV Metodología}

\section{Enfoque:}

Esta investigación se realizará desde un enfoque cualitativo experimental pues se aplicarán las mismas estrategias educativas a dos niños con el propósito de observar las características de cada uno y las diferencias que existen entre ellos y finalmente percatarse de la influencia de las estrategias en sus conductas.

\section{Disciplina:}

La disciplina desde la cual se estudiará esta investigación será la pedagogía con orientación familiar.

\section{Objetivo:}

EL objetivo que persigue la investigación es brindar a los padres estrategias educativas para niños de 1 a 3 años que estimulen sus áreas de desarrollo. 


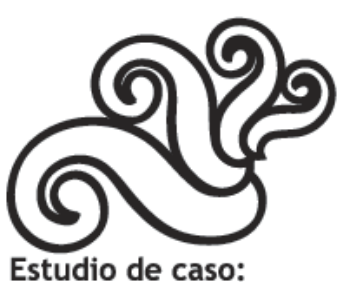

La aplicación de las estrategias será un estudio de caso, pues se aplicará únicamente a dos niños.

\section{Contexto:}

EL contexto que rodea a cada uno de los sujetos es distinto, pues será interesante observar la manera en que éste influye en el desarrollo.

- Ángel que es uno de los sujetos posee un nivel socioeconómico alto, sus padres tienen un nivel académico medio, vive en un ambiente familiar estable, tiene dos hermanas, convive con niños y otras personas continuamente, sus padres le brindan atención, recibe una buena alimentación y cuenta con material que estimula su desarrollo cognitivo.

- Gustavo posee un nivel socioeconómico bajo, uno de sus padres tiene nivel académico básico, vive en un ambiente familiar estable, es hijo único, convive muy poco con niños y otras personas, su mamá no le da tanta atención, no recibe una buena alimentación y cuenta con poco material que estimule su aprendizaje.

Los sujetos:

Las personas que se estudiaron en esta investigación son dos niños de diferentes edades, uno de tres años y otro de 2 años 10 meses, con niveles socioeconómicos distintos, numero de familiares distintos y edades de padres similares.

\section{El lugar:}

EL lugar donde se llevaron a cabo las actividades fue en Tizayuca Hidalgo durante el mes de abril del 2006.

\section{Instrumentos:}

A lo largo de la investigación se usaron distintos instrumentos para recolectar datos, tales como la entrevista y la guía de observación a través de las cuales se pudieron recuperar referencias importantes de cada niño. A través de estos datos se pueden percibir las características de cada niño, sus diferencias y a partir de ellas llegar a resultados y conclusiones.

\section{El procedimiento:}

El procedimiento que se llevó a cabo para la realización de la investigación fue el siguiente:

- Buscar un problema dentro de la sociedad; en este caso las familias carecen de estrategias educativas suficientes para educar a sus hijos.

- Formular una pregunta de investigación; en este caso la pregunta de investigación es ipor qué es importante iniciar la educación en los hijos desde sus primeros años? Con base a esta pregunta se inició este trabajo.

- Justificar el tema; es decir describir por qué sería relevante estudiar a niños, la justificación es que al crear estrategias educativas en niños de 1 a 3 años se verían beneficiadas muchas familias al mejorar la calidad de vida de sus hijos y por tanto su ambiente familiar.

- Establecer los alcances y objetivos; en el caso de esta investigación el objetivo principal es ofrecer a los padres estrategias educativas que ayuden al niño en su desarrollo para mejorar su calidad de vida.

- Realizar la búsqueda de documentos teóricos que sustentaran el trabajo; como son las teorías de Piaget, Erikson y Freud acerca del desarrollo del niño.

- Buscar a sujetos representativos del área investigada; en este caso fueron dos niños con características distintas.

- Realizar un diseño de investigación en el que se establezcan las actividades a realizar. El área que se trabajará en los niños y los días que se realizará.

- Aplicar las estrategias.- Durante varios días para cubrir las actividades de cada área.

Recolección de datos; a través de entrevistas que se aplicarán a las madres y la observación realizada a lo largo de las estrategias.

- Analizar los datos obtenidos en las entrevistas y observaciones.

- Contrastar la teoría investigada con los datos obtenidos. 
- Redactar los resultados y conclusiones a los que se llegaron después del análisis.

Guía de observación

\begin{tabular}{|c|c|c|c|}
\hline Fecha & Actividad a realizar & $\begin{array}{c}\text { Como se realizará la } \\
\text { actividad }\end{array}$ & $\begin{array}{l}\text { Recursos } \\
\text { materiales }\end{array}$ \\
\hline $\begin{array}{l}10 \text { de abril del } \\
2006 \\
\text { DESARROLLO } \\
\text { FÍsICO } \\
\text { a) Peso y talla } \\
\text { b) Alimentación }\end{array}$ & $\begin{array}{l}\text { Se revisará el } \\
\text { desarrollo físico del } \\
\text { niño. } \\
\text { Se anotará } \\
\text { el peso y la talla } \\
\text { de cada uno de los } \\
\text { niños. } \\
\text { Se realizarán algunas } \\
\text { preguntas a las } \\
\text { madres acerca de la } \\
\text { alimentación que el } \\
\text { niño lleva. Se hablará } \\
\text { sobre el control de } \\
\text { esfínteres. }\end{array}$ & $\begin{array}{l}\text { La actividad se realizará en } \\
\text { mi casa, con una báscula } \\
\text { y una cinta métrica. Se } \\
\text { medirá y pesará a cada } \\
\text { niño. } \\
\text { A través de un cuestionario } \\
\text { que las madres contestarán } \\
\text { se detectará si la } \\
\text { alimentación que el niño } \\
\text { lleva afecta su crecimiento. } \\
\text { Se les darán algunos } \\
\text { consejos a las madres para } \\
\text { mejorar la alimentación del } \\
\text { niño y para ayudar en el } \\
\text { proceso de enseñanza del } \\
\text { control de esfínteres. }\end{array}$ & $\begin{array}{l}\text { Cinta métrica } \\
\text { Báscula } \\
\text { Cuestionario }\end{array}$ \\
\hline $\begin{array}{l}11 \text { de abril del } \\
2006 \\
\text { y } 12 \text { de abril del } \\
2006 \\
\text { II } \\
\text { PSICOMOTRICi- } \\
\text { DAD } \\
\text { a) Motridad fina } \\
\text { y gruesa. } \\
\text { b) Destrezas } \\
\text { manuales }\end{array}$ & $\begin{array}{l}\text { Se trabajará el área } \\
\text { de Psicomotricidad } \\
\text { del niño. } \\
\text { El tema será } \\
\text { Motricidad } \\
\text { fina y gruesa. } \\
\text { Se ejercitarán } \\
\text { movimientos finos } \\
\text { de manos y pies, } \\
\text { coordinación fono } \\
\text { - articuladora, } \\
\text { coordinación óculo- } \\
\text { motora y equilibrio } \\
\text { del cuerpo. Al } \\
\text { mismo tiempo } \\
\text { se desarrollará } \\
\text { su creatividad, } \\
\text { capacidades } \\
\text { artísticas y destrezas } \\
\text { manuales. }\end{array}$ & $\begin{array}{l}\text { Esta área trabajará con } \\
\text { música, a los niños se } \\
\text { les enseñarán algunos } \\
\text { movimientos y cambios de } \\
\text { posición de su cuerpo que } \\
\text { coincidirán con la letra } \\
\text { musical. } \\
\text { Al siguiente día al niño se } \\
\text { le proporcionarán pinturas, } \\
\text { papel, lápices para que él } \\
\text { dibuje lo que quiera. Al } \\
\text { término de esa actividad se } \\
\text { le dará papel para que haga } \\
\text { bolitas. }\end{array}$ & $\begin{array}{l}\text { Grabadora } \\
\text { Discos } \\
\text { musícales } \\
\text { Papel } \\
\text { Pinceles } \\
\text { Pintura digital } \\
\text { Lápices de } \\
\text { colores } \\
\text { Mandil para } \\
\text { niño } \\
\text { Papel crepe } \\
\text { Guía de } \\
\text { observación }\end{array}$ \\
\hline
\end{tabular}




\begin{tabular}{|c|c|c|c|}
\hline $\begin{array}{l}13 \text { de abril del } \\
2006 \\
\text { c) percepción }\end{array}$ & $\begin{array}{l}\text { Se trabajará el área } \\
\text { de Psicomotricidad. } \\
\text { El tema será el } \\
\text { desarrollo sensorial o } \\
\text { percepción. Además } \\
\text { de que ejercitará } \\
\text { su memoria y la } \\
\text { semejanza entre } \\
\text { objetos con los } \\
\text { juegos que se } \\
\text { realizarán. }\end{array}$ & $\begin{array}{l}\text { Se le presentará a cada } \\
\text { uno de los niños distintas } \\
\text { texturas, temperaturas, } \\
\text { olores, sabores, figuras } \\
\text { de distintas formas y } \\
\text { sonidos. Con la finalidad de } \\
\text { desarrollar sus sentidos. } \\
\text { Después de que cada niño } \\
\text { pruebe los sabores tendrá } \\
\text { que acomodarlos del que } \\
\text { más le gustó al que menos } \\
\text { le gustó. } \\
\text { Los olores estarán en } \\
\text { pequeños frascos y tendrán } \\
\text { a su pareja. } \\
\text { Después de que cada niño } \\
\text { perciba los tipos de olores } \\
\text { tendrá que reconocerlos } \\
\text { y acomodarlos por pares } \\
\text { iguales, por ejemplo: } \\
\text { café con café u orégano } \\
\text { con orégano. Este mismo } \\
\text { ejercicio se hará con las } \\
\text { texturas. } \\
\text { Después de que el niño } \\
\text { escuche todos los sonidos } \\
\text { tendrá que reconocer y } \\
\text { decir qué tipo de animal } \\
\text { es o qué tipo de música le } \\
\text { gustó más. }\end{array}$ & $\begin{array}{l}\text { Texturas: lija } \\
\text { Peluche } \\
\text { Esponja } \\
\text { Arena } \\
\text { Piedras } \\
\text { Tela } \\
\text { Agua caliente } \\
\text { y fría } \\
\text { Madera } \\
\text { Olores: } \\
\text { aromati-zante } \\
\text { perfume } \\
\text { orégano } \\
\text { café } \\
\text { manzanilla } \\
\text { canela } \\
\text { sabores: limón } \\
\text { café } \\
\text { miel } \\
\text { azúcar } \\
\text { chile } \\
\text { sonidos: } \\
\text { animales } \\
\text { botellas con } \\
\text { piedras y arroz } \\
\text { Música de } \\
\text { diferentes } \\
\text { géneros. } \\
\text { aro } \\
\text { Guía de } \\
\text { observación }\end{array}$ \\
\hline $\begin{array}{l}13 \text { de abril del } \\
\quad 2006 \\
\text { d) Lateralidad y } \\
\text { elaboración de } \\
\text { espacio. } \\
\text { e) Esquema } \\
\text { corporal. }\end{array}$ & $\begin{array}{l}\text { Se trabajará el área } \\
\text { de Psicomotricidad } \\
\text { El tema es } \\
\text { lateralidad y } \\
\text { elaboración de } \\
\text { espacio. También se } \\
\text { ejercitará la memoria } \\
\text { del niño } \\
\text { Se trabajará también } \\
\text { el tema } \\
\text { Esquema corporal }\end{array}$ & $\begin{array}{l}\text { A través de una canción } \\
\text { se le enseñarán al niño los } \\
\text { términos atrás-adelante, } \\
\text { abajo- arriba, derecha- } \\
\text { izquierda. } \\
\text { Se le enseñará al niño el } \\
\text { nombre de algunas partes } \\
\text { de su cuerpo. Después él } \\
\text { tendrá que identificarlas en } \\
\text { su cuerpo y en el de otros } \\
\text { niños y también en dibujos } \\
\text { y revistas }\end{array}$ & $\begin{array}{l}\text { Grabadora } \\
\text { Discos } \\
\text { musicales } \\
\text { Pelota } \\
\text { Canciones con } \\
\text { las partes del } \\
\text { cuerpo } \\
\text { Revistas y } \\
\text { dibujos } \\
\text { Guía de } \\
\text { observación }\end{array}$ \\
\hline
\end{tabular}




\begin{tabular}{|c|c|c|c|}
\hline $\begin{array}{l}14 \text { de abril del } \\
2006 \\
\\
\text { III } \\
\text { DESARROLLO } \\
\text { COGNITIVO. } \\
\\
\\
\text { a) Comprensión } \\
\text { de } \\
\text { identidades. } \\
\text { b) Uso de } \\
\text { símbolos. } \\
\text { Noción de } \\
\text { objeto y } \\
\text { personas. }\end{array}$ & $\begin{array}{l}\text { El área a trabajar } \\
\text { será cognitiva o de } \\
\text { razonamiento. El } \\
\text { tema será noción } \\
\text { del objeto y de la } \\
\text { persona. } \\
\text { La finalidad es que } \\
\text { el niño conozca } \\
\text { a su familia, a } \\
\text { sus compañeros } \\
\text { comunitarios y a } \\
\text { personas extrañas. }\end{array}$ & $\begin{array}{l}\text { Se manejará la } \\
\text { trasformación de objetos sin } \\
\text { alteración de la sustancia. } \\
\text { Por ejemplo: hacer } \\
\text { diferentes formas con } \\
\text { plastilina o construcción de } \\
\text { distintas figuras con tierra y } \\
\text { después con lodo. Poner en } \\
\text { vasos de distinto tamaño la } \\
\text { misma cantidad de refresco } \\
\text { y preguntar al niño cual de } \\
\text { los dos tiene más o cual de } \\
\text { los dos prefiere. } \\
\text { Al término de estas } \\
\text { actividades al niño se le } \\
\text { enseñarán las fotos y los } \\
\text { nombres de sus familiares } \\
\text { y de las personas extrañas; } \\
\text { después se mostrará la foto } \\
\text { y él tendrá que reconocerlas } \\
\text { y decir quiénes son. }\end{array}$ & $\begin{array}{l}\text { Plastilina } \\
\text { Tierra o arena } \\
\text { Vasos } \\
\text { Refresco } \\
\text { Fotografías de } \\
\text { Familiares } \\
\text { Fotografías de } \\
\text { policía, doctor, } \\
\text { maestro, } \\
\text { veterinario. } \\
\text { Mandil para } \\
\text { niño } \\
\text { Guía de } \\
\text { observación }\end{array}$ \\
\hline $\begin{array}{l}17 \text { de abril del } \\
2006\end{array}$ & $\begin{array}{l}\text { Se trabajará el } \\
\text { área cognitiva o } \\
\text { de razonamiento. } \\
\text { El tema será } \\
\text { clasificación, relación } \\
\text { entre causa- efecto. }\end{array}$ & $\begin{array}{l}\text { Se le enseñarán al niño los } \\
\text { términos grande y pequeño. } \\
\text { Después se le brindarán } \\
\text { varios objetos de distintos } \\
\text { tamaños y él tendrá que } \\
\text { señalar cuál es el más } \\
\text { grande y cuál es el más } \\
\text { pequeño, una vez que el } \\
\text { niño ubique los términos, } \\
\text { tendrá que ordenarlos de } \\
\text { mayor a menor. Al terminar } \\
\text { la actividad el niño probará } \\
\text { en distintas circunstancias, } \\
\text { la cusa y efecto. Por } \\
\text { ejemplo, se le enseñará al } \\
\text { niño que si apachurra un } \\
\text { botó se producirá un sonido } \\
\text { o se prenderá la televisión. } \\
\text { Si le sopla a una vele } \\
\text { encendida está se apagará. }\end{array}$ & $\begin{array}{l}\text { Objetos: } \\
\text { muñecos } \\
\text { Figuras } \\
\text { Dulces de } \\
\text { distintos } \\
\text { tamaños. } \\
\text { Juguete } \\
\text { que produce } \\
\text { sonidos } \\
\text { Televisión y } \\
\text { control } \\
\text { vela } \\
\text { Guía de } \\
\text { observación }\end{array}$ \\
\hline
\end{tabular}




\begin{tabular}{|c|c|c|c|}
\hline $\begin{array}{l}18 \text { de abril del } \\
2006 \\
\text { IV } \\
\text { DESARROLLO DEL } \\
\text { LENGUAJE. } \\
\text { a) Expresión y } \\
\text { comprensión } \\
\text { verbal. }\end{array}$ & $\begin{array}{l}\text { Se trabajará con el } \\
\text { lenguaje. } \\
\text { El tema será } \\
\text { expresión verbal y } \\
\text { comprensión verbal. }\end{array}$ & $\begin{array}{l}\text { Se trabajará con canciones, } \\
\text { en las cuales el niño y la } \\
\text { madre tendrán que catar. } \\
\text { Se les darán a las madres } \\
\text { algunas recomendaciones } \\
\text { para ayudar a mejorar el } \\
\text { lenguaje de su hijo. }\end{array}$ & $\begin{array}{l}\text { Grabadora } \\
\text { Discos } \\
\text { musicales } \\
\text { Guía de } \\
\text { observación } \\
\text { Cuestionario }\end{array}$ \\
\hline $\begin{array}{l}9 \text { de abril del } \\
2006 \\
\text { v } \\
\text { DESARROLLO } \\
\text { PSICOSOCIAL } \\
\text { a) Interacción } \\
\text { afectiva y social. } \\
\text { c)Los valores. } \\
\text { d)Formación del } \\
\text { yo. }\end{array}$ & $\begin{array}{l}\text { El área que se } \\
\text { trabajará es } \\
\text { Psicosocial y } \\
\text { afectiva. El tema } \\
\text { será: interacción } \\
\text { afectiva y social. } \\
\text { Inculcar valores } \\
\text { es importante en } \\
\text { la formación de los } \\
\text { niños. } \\
\text { Formación del yo y } \\
\text { la importancia de la } \\
\text { autonomía. }\end{array}$ & $\begin{array}{l}\text { Se les prestarán a los } \\
\text { niños algunos carritos y se } \\
\text { le indicará que jueguen } \\
\text { durante algunos minutos, } \\
\text { después se les prestará un } \\
\text { juguete a todos y tendrán } \\
\text { que compartir y esperar su } \\
\text { turno. } \\
\text { A los padres se le darán } \\
\text { recomendaciones para } \\
\text { mejorar la socialización del } \\
\text { niño: } \\
\text { Dar atención y afecto } \\
\text { al niño para brindarle } \\
\text { confianza y seguridad. } \\
\text { Finalmente se dará una } \\
\text { pequeña explicación a las } \\
\text { madres de los valores y su } \\
\text { importancia en la formación } \\
\text { de sus hijos. }\end{array}$ & $\begin{array}{l}\text { Carritos } \\
\text { Mesa pequeña } \\
\text { Guía de } \\
\text { observación. } \\
\text { Cuestionario }\end{array}$ \\
\hline $\begin{array}{l}20 \text { de abril del } \\
2006 \\
\text { e) Cuidado de la } \\
\text { naturaleza. }\end{array}$ & $\begin{array}{l}\text { Se trabajará el área } \\
\text { Psicosocial del niño. } \\
\text { El tema será el } \\
\text { hábitat. La finalidad } \\
\text { es que los niños } \\
\text { aprendan a cuidar el } \\
\text { medio que los rodea. }\end{array}$ & $\begin{array}{l}\text { Se les enseñará a los niños } \\
\text { a regar las plantas, a cuidar } \\
\text { el agua, a tirar la basura } \\
\text { en el bote y se les explicará } \\
\text { que es importante que las } \\
\text { cuiden. Para finalizar las } \\
\text { actividades se llevará a los } \\
\text { niños con animales como } \\
\text { cerdos, borregos, gallinas y } \\
\text { perros para que les den de } \\
\text { comer y explicarles que es } \\
\text { importante cuidarlos. } \\
\text { Agradeceré a las madres su } \\
\text { participación }\end{array}$ & $\begin{array}{l}\text { Agua Regaderas } \\
\text { Basura y bote } \\
\text { de basura } \\
\text { Comida para } \\
\text { animales y } \\
\text { animales } \\
\text { Un parque o } \\
\text { plantas. } \\
\text { Guía de } \\
\text { observación }\end{array}$ \\
\hline
\end{tabular}




\section{Capítulo V Resultados}

En base a las observaciones, las entrevistas y las estrategias aplicadas los resultados obtenidos fueron los siguientes:

Durante la aplicación de las estrategias se pudo observar que cada niño vive en un contexto o ambiente familiar muy distinto y que reciben estimulación diferente por lo cual el desarrollo de cada infante es diferente.

Se descubrió que el niño A que es Gustavo tiene un menor desarrollo en sus áreas que el niño B que es Ángel.

El desarrollo físico del niño $A$ es menor que el del niño $B$ debido a la mala nutrición que lleva, su estatura es alta sin embargo su peso es bajo en comparación con el del niño $B$ que es menor que él.

El niño $B$ que tiene 2 años 10 meses comenzó su entrenamiento de control de esfínteres desde los 2 años, que es la edad adecuada para iniciar el entrenamiento según Freíd; en cambio el niño A que tiene tres años tiene 15 días que lo inició.

Se encontró que el desarrollo psicomotor del niño A era menor que el del niño $B$, pues el niño A presentó varios problemas durante la aplicación de las estrategias, en los movimientos gruesos como correr y saltar; $y$ el niño $B$ no tuvo ningún problema, Sin embargo en los movimientos finos como hacer bolitas de crepe con los dedos demostró serias dificultades, aunque después de practicar logró mejorar un poco. Mientras que el niño $B$ pudo realizar los ejercicios sin ningún conflicto.

El niño A desconocía muchas partes de su cuerpo, términos como adelante, atrás, izquierda, derecha los cuales ya eran conocidos por el niño B. A largo de las actividades se observó que el niño A tuvo problemas para percibir los diferentes olores, sabores, sonidos y texturas; el niño $B$ los reconoció fácilmente sin problemas.

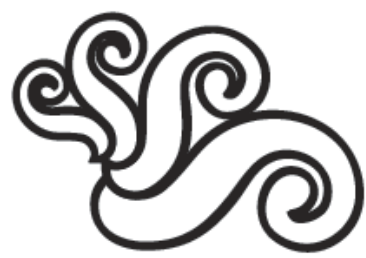

En las actividades artísticas ambos niños se sintieron muy tranquilos y se divirtieron.

El desarrollo psicosocial en cada niño estuvo muy marcado en los días que se trabajó con ellos. El niño B reflejó todo el tiempo cierta habilidad para establecer conversaciones con otras personas, para convivir con facilidad, mientras que el niño A siempre se encontraba apartado, cerca de su mamá y todo el tiempo se mostró tímido. Para el niño $B$ era más fácil ser sociable pues la mayor parte del tiempo convive con niños y el niño A convive más tiempo con su mamá y papá.

El niño A demostró menos autonomía que el niño $B$, pues la mayor parte del tiempo quería estar con su mamá, pero el niño B se mostró más posesivo ya que le costaba más trabajo compartir sus cosas que al otro niño.

Las actividades en las que a los niños se les enseñó a cuidar la naturaleza y los animales no resultaron como se creía, puesto que el niño A le tenía pánico a los animales. Para el niño B fue divertido dar de comer a los animales, recolectar frutas y regar las plantas.

El desarrollo lingüístico del niño $A$ era mucho menor que el del niño B, pues el A hablaba muy poco y las palabras las pronunciaba mal, las instrucciones que se le daban pocas veces las entendía. El niño B se expresaba mejor, usaba oraciones y pocas de las palabras que utilizaba estaban mal pronunciadas, además de que las instrucciones si las entendía. El lenguaje del niño A era deficiente por la poca estimulación que recibe y por la poca convivencia que tiene con otras personas.

Se percibió a lo largo de las observaciones que el niño con menor desarrollo cognitivo fue el niño A pues la poca estimulación, que su ambiente le brinda le ha truncado un poco.

El niño A no pudo clasificar algunos de los objetos que se le prestaron, si supo identificar las causas que provocaban un efecto y pudo reconocer con facilidad a sus familiares en fotos. El niño B realizó estas actividades con mayor facilidad. 


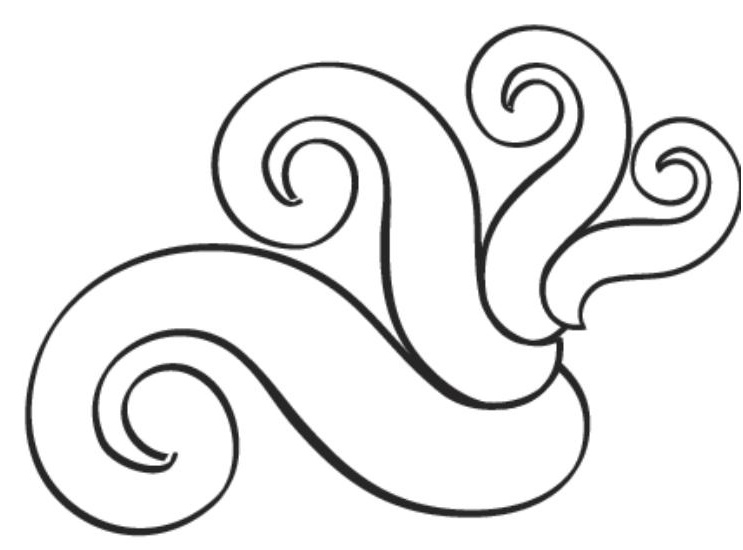

\section{Capítulo VI Conclusiones}

Al término de esta investigación y después de haber analizado los datos obtenidos durante las observaciones se ha llegado a lo siguiente:

Uno de los objetivos principales de este trabajo fue promover el desarrollo personal del niño a través de oportunidades que le permitieran ampliar y mejorar su lenguaje, psicomotricidad, desarrollo cognitivo y afectividad.

En cuanto al desarrollo físico se puede concluir que existen distintos factores como la economía familiar, genética, horarios alimenticios y tipo de alimentación que determinan el desarrollo físico en cada uno de los niños. Un ejemplo es que Ángel aunque era más pequeño que Gustavo tenia mayor peso, y un mejor desarrollo en las demás áreas. El desarrollo físico también influye en que las otras áreas se puedan desarrollar, éste podría ser un factor que interviene para que el desarrollo de Gustavo sea menor que el de Ángel.

El desarrollo cognitivo está influido por la herencia, la experiencia y otros factores que ya se mencionaron anteriormente. En el caso de Gustavo, el desarrollo cognitivo era menor por la falta de estimulación.

La posición socioeconómica también tiene influencia en el desarrollo cognitivo del niño, ya que la capacidad de los padres para proporcionar recursos educativos son menores y frenan el crecimiento. La atención que los padres brinden a sus hijos también influye en su desarrollo.

El desarrollo cognitivo que se observó en cada uno de los niños está directamente influenciado por cada uno de los factores antes mencionados, Ángel presentó un mejor desarrollo cognitivo que Gustavo porque efectivamente tiene una buena interacción familiar, sus padres le dan la atención necesaria, tiene un buen desarrollo físico además de tener la suerte de gozar de una buena posición económica.

El desarrollo psicosocial del niño depende en gran parte de la relación y del apego que el niño haya tenido con su madre durante los primeros años, del ambiente familiar, de la interacción entre padres e hijos, de la interacción con otros niños y adultos, de los valores fomentados en el niño. Cada uno de lo factores se vieron reflejados en el comportamiento pues para Ángel era más fácil socializar que para Gustavo, debido a que Ángel convivía continuamente con más personas que Gustavo.

El desarrollo psicomotriz del niño está determinado por factores como el desarrollo físico, el desarrollo cognitivo, pero en especial por la estimulación recibida por el medio. Gustavo presentó un menor desarrollo psicomotriz en parte porque desde pequeño tuvo un problema en la columna pero además recibe muy poca estimulación por lo que no ha desarrollado al máximo su capacidad de movimiento.

El desarrollo lingüístico también se ve afectado por la estimulación que el niño reciba, su desarrollo físico y del ambiente en el que esté creciendo. Ángel a pesar de ser menor que Gustavo pronunciaba mejor las palabras y se expresaba mejor.

El desarrollo de los niños se encuentra influenciado directamente por el contexto que lo rodea, por tal motivo es importante presentarles herramientas que les permitan alcanzar un desarrollo óptimo.

Alo largo de esta investigación se pudo observar que cada niño tiene un ritmo de aprendizaje distinto y que es importante respetarlo y entender que el contexto en el que se está inmerso influye de forma determinante en su personalidad y desarrollo.

A pesar de que existen muchos factores que determinan el desarrollo de los niños podemos 


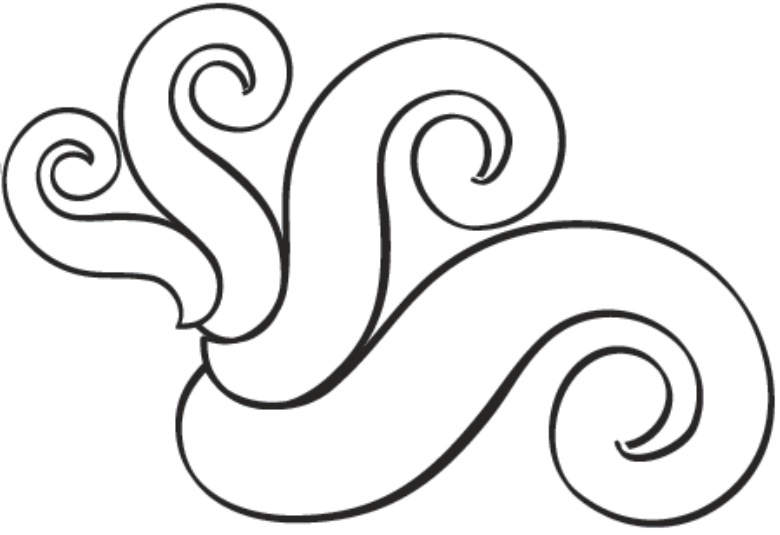

concluir que la edad no es tan determinante como la estimulación que los padres y el ambiente brinden, que es importante que los padres estén conscientes de que la labor educativa es una gran responsabilidad debido a que, con base a ella, sus hijos tendrán un mejor desarrollo y por lo tanto una mejor estancia dentro de la sociedad.

\section{Bibliografía}

Abad, Amaro, Anaya y Asensi (1992). Programa de educación inicial. México: S E P

Calderón, Sánchez y Suárez (2003). Estimulación temprana. México: Reymo

Casas de la Torre, Esquivel, Licona y Uribe (1997). Diccionario de las ciencias de la educación. España: Aula Santillana

Durivage, J (2000). Educación y Psicomotricidad. México: Trillas

Papalia, Olds y Feldman (2005). Desarrollo

Humano. México: McGraw Hill

Van Cube, F (1981). La ciencia de la educación.

España: Ceac

Tabla de peso y talla, recuperado el 15 de mayo del 2006 de http: //www. crecerjuntos. com.ar/tablas. htm

\section{Anexos}

\section{Cuestionario}

Datos de padres.

Nombre:

Edad:

Ocupación:

Nivel académico:

Lugar donde vive

Datos del niño.

Nombre:

Edad:

Sexo:

Área desarrollo Físico

1. ¿Su hijo cumple con el peso ideal?

$$
\text { a)si b)no }
$$

2. ¿Complementa la alimentación de su hijo con vitaminas?

$$
\text { a)si b)no }
$$

3. ¿Tiene horarios establecidos para las comidas?

$$
\text { a)si b)no }
$$

4. ¿Cuántas comidas realizan durante el día?

$$
\begin{array}{ll}
\text { a) } 3 \text { a } 4 & \text { b) } 1 \text { a } 2
\end{array}
$$

5. ¿Cuantas veces al día come toda la familia?
a) 2 a 3 veces
b) 1 vez

6. ¿Tiene problemas con su hijo porque no quiere comer?

$$
\text { a)si b)no }
$$

7. ¿Ha comenzado con el entrenamiento de control de esfínteres con su hijo?

$$
\text { a)si b)no }
$$

8. ¿A qué edad comenzó el entrenamiento?
a) 18 a 24 meses
b) 24 a 36 meses

9. ¿Utilizó algún castigo o premio durante el entrenamiento?
a)si
b)no

Área de desarrollo Psicomotriz

1. ¿Su hijo se mueve con facilidad?

$$
\text { a)si b)no }
$$

2. ¿Su hijo puede subir una escalera por si sólo y correr con facilidad?

$$
\text { a)si b)no }
$$

3. ¿Su hijo pude tomar un lápiz y escribir y tomar bien la cuchara para comer?

$$
\text { a)si b)no }
$$

4. ¿Su hijo conoce las partes de su cuerpo?
a)si
b)no

5. ¿Su hijo conoce los términos: derecha, izquierda, arriba, abajo, antes y después?

$$
\text { a)si b)no }
$$

6. ¿Su hijo conoce el camino para llegar a su casa?

$$
\text { a)si b)no }
$$

7. ¿Su hijo realiza actividades artísticas como pintar o dibujar?

$$
\text { a)si b)no }
$$

8. ¿Suele imitar a los adultos?
a)si
b)no

9. ¿Su hijo puede distinguir entre distintas texturas, sonidos, olores, colores y formas?

$$
\text { a)si b)no }
$$

Área de desarrollo cognitivo

${ }_{1}$ Cree que su hijo puede aprender de manera más rápida si se le da algún tipo de premio?
a)si
b) no

2. ¿Cuenta con juguetes como rompecabezas, cubos para construir, objetos que produzcan algún sonido u objetos para clasificar?
a)si
b)no

3. ¿Lee a su hijo, cuentos o revistas?
a)si b)no

4. ¿Su hijo conoce algunos números y letras?
a)si
b)no

5. ¿Su hijo conoce el nombre de algunos animales $y$ frutas?

a)si b)no

6. ¿Su hijo puede identificar colores, formas y tamaños?

a)si b)no




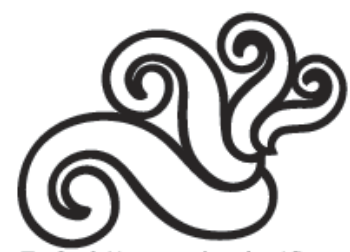

7 ¿Su hijo puede clasificar objetos por tamaño, colores o forma?
a)si
b)no

8. ¿Su hijo puede distinguir a su familia en fotografías?
a)si
b) no

9. ¿Su hijo sabe de las consecuencias, si tiene un mal comportamiento?

$$
\text { a)si b)no }
$$

Área de desarrollo de lenguaje

1. ¿El niño se comunica con usted más con señales que con palabras?

$$
\text { a)si b)no }
$$

2. ¿La mayoría de las palabras que su hijo dice son bien pronunciadas?

$$
\text { a)si b)no }
$$

3. ¿Usted corrige al niño cuando dice de manera incorrecta una palabra?
a)si
b) no

4. ¿Usted es la única persona que entiende a su hijo cuando habla?

$$
\text { a)si b)no }
$$

5. ¿Su hijo ya utiliza oraciones para comunicarse?

$$
\text { a)si b)no }
$$

6. ¿Su hijo comprende las órdenes que usted le da?

$$
\text { a)si b)no }
$$

7. ¿Usted lee cuentos o rimas a su hijo?

$$
\text { a)si b)no }
$$

8. ¿Usted canta con su hijo?

$$
\text { a)si b)no }
$$

9. ¿Usted platica con su hijo y le explica situaciones que él no comprende?

$$
\text { a)si b)no }
$$

Área de desarrollo Psicosocial

1. ¿Para su hijo es fácil relacionarse con personas desconocidas?

$$
\text { a)si b)no }
$$

2. ¿Su hijo convive más con niños que con adultos?
a)si
b)no

3. ¿Da oportunidad a su hijo de hacer las cosas por sí solo?

$$
\text { a)si b)no }
$$

4 ¿Su hijo hace berrinches con mucha frecuencia?

$$
\text { a)si b)no }
$$

5. ¿Su hijo suele compartir sus cosas con otras personas?

$$
\text { a)si b)no }
$$

6. ¿Su hijo trata de atraer siempre su atención?
a)si
b) no

7. ¿Cree que su hijo es muy pequeño para empezar a fomentar valores en él?
a)si
b)no

8. ¿Ha enseñado a su hijo a cuidara a los animales y las plantas?
a)si
b)no

9 ¿Ha enseñado a su hijo a cuidar el agua y a tirar la basura en su lugar?
a)si
b)no

Análisis de los datos

A lo largo de esta investigación fueron creadas algunas estrategias educativas para infantes de 1 a 3 años de edad las cuales se aplicaron con los niños que presentan los siguientes datos:

Datos del niño: $A$

Nombre: Gustavo Alejandro Ríos Reséndiz

Edad: 3 años

Datos de sus padres: $B$

Nombre: Karla Janet Reséndiz Hernández

Edad: 21 años

Ocupación: ama de casa

Nivel académico: preparatoria

Nombre de papá: Gustavo Ríos Sánchez

Edad: 26 años

Ocupación: comerciante

Nivel académico: primaria

Datos del niño:

Nombre: Luis Ángel Quezada Rubio

Edad: 2 años 10 meses

Datos de sus padres:

Nombre: Lina Karen Rubio Muñoz

Edad: 21 años

Ocupación: ama de casa

Nivel académico: preparatoria

Nombre de papá: José Luis Quezada Sánchez

Edad: 25 años

Ocupación: comerciante

Nivel académico: preparatoria

Durante la aplicación de las estrategias se pudieron observar las diferencias que existían en entre cada niño en cuanto a su desarrollo físico, emocional, cognitivo, motriz y lingüístico.

Las técnicas utilizadas para recopilar los datos fueron la entrevista y la observación. 


\begin{tabular}{|c|c|}
\hline \multicolumn{2}{|c|}{ Cuadro comparativo } \\
\hline Luis Ángel Quezada Rubio & Gustavo Alejandro Ríos Reséndiz \\
\hline $\begin{array}{l}\text { Desarrollo Físico: Ángel superó la estatura y el } \\
\text { peso ideal. Él pesó17.3 Kg. midió } 97 \mathrm{~cm} \text {. } \\
\text { Ángel tiene } 10 \text { meses que inició con su } \\
\text { entrenamiento de control de esfínteres, } \\
\text { actualmente no usa pañal y va sólo al baño. }\end{array}$ & $\begin{array}{l}\text { Desarrollo Físico: Gustavo también superó la } \\
\text { estatura y el peso ideal. Él } \\
\text { Pesó } 16.9 \mathrm{Kg} \text {. midió } 103 \mathrm{~cm} \text {. } \\
\text { Gustavo tiene } 15 \text { días que inició con su } \\
\text { entrenamiento, tampoco usa pañal pero aun no } \\
\text { va sólo al baño. }\end{array}$ \\
\hline $\begin{array}{l}\text { Desarrollo Psicomotriz: durante la aplicación de } \\
\text { las estrategias se pudo observar que Ángel no tiene } \\
\text { problemas en cuanto a movimientos gruesos ya que } \\
\text { corre y sube una escalera sin ningún problema. } \\
\text { Antes de la aplicación de las estrategias, para } \\
\text { Ángel eran difícil los movimientos finos pero } \\
\text { después de estar practicando mejoró, un ejemplo } \\
\text { es que ya podía hacer bolitas de papel crepe. } \\
\text { En cuanto noción corporal Ángel conocía el nombre } \\
\text { de muchas partes de su cuerpo y algunas otras que } \\
\text { desconocía las aprendió mediante las estrategias. } \\
\text { Ángel ya conocía los términos arriba, abajo, atrás } \\
\text { y adelante (ubicación espacial) pero le faltaba } \\
\text { distinguir entre derecha e izquierda así que con } \\
\text { un juego y algunas canciones logró aprender la } \\
\text { diferencia. } \\
\text { En los ejercicios de percepción que se aplicaron, } \\
\text { Ángel no tuvo problemas para reconocer los } \\
\text { diversos olores, sabores, sonidos y texturas. } \\
\text { La actividad artística resultó muy relajante y } \\
\text { divertida para Ángel. }\end{array}$ & $\begin{array}{l}\text { Desarrollo Psicomotriz: durante la aplicación } \\
\text { de estrategias se pudo observar que Gustavo } \\
\text { no tiene problemas en cuanto a movimientos } \\
\text { gruesos ya que corre y sube una escalera sin } \\
\text { ningún problema, aunque lo hace con mucho } \\
\text { cuidado porque de pequeño tuvo un problema en } \\
\text { su columna. Durante la aplicación de estrategias } \\
\text { se pudo observar que para Gustavo resultó } \\
\text { muy difícil los movimientos finos, un ejemplo } \\
\text { es que no podía hacer bolitas de papel crepe, a } \\
\text { él únicamente le salían palitos, después de que } \\
\text { estuvo practicando en casa con su mamá mejoró } \\
\text { pero muy poco. } \\
\text { En cuanto noción corporal Gustavo no conocía el } \\
\text { nombre de muchas partes de su cuerpo pero con } \\
\text { los juegos y canciones logró aprenderse algunas. } \\
\text { Gustavo no conocía los términos arriba, abajo, } \\
\text { atrás y adelante (ubicación espacial) ni sabía } \\
\text { distinguir entre derecha e izquierda así que con } \\
\text { un juego y algunas canciones logró aprender sólo } \\
\text { arriba y abajo los demás términos los confundía. } \\
\text { En los ejercicios de percepción que se aplicaron, } \\
\text { Gustavo tuvo muchos problemas para reconocer } \\
\text { los diversos olores, sabores, sonidos y texturas. } \\
\text { La actividad artística resulto muy relajante } \\
\text { y divertida para Gustavo, le gustó tanto que } \\
\text { decidió hacer varios dibujos. }\end{array}$ \\
\hline
\end{tabular}




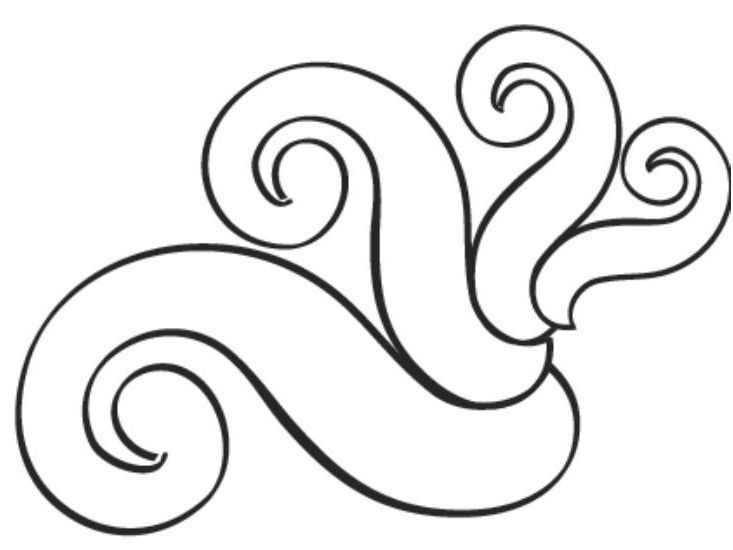

Desarrollo Psicosocial: Se pudo percibir que para Ángel es muy fácil establecer una conversación con cualquier tipo de gente, desde niños hasta adultos, además de que refleja mucha confianza durante sus relaciones. Para él es más fácil porque convive continuamente con más niños y tiene dos hermanitas.

A veces era un poco posesivo con sus cosas y aunque le costaba trabajo compartirlas finalmente lo hacía. Nunca lo vi hacer un berrinche pero si logré ver que era un poco enojón.

La relación que hay entre él y su madre es buena pero él ya no se encuentra muy apegado a ella, su conducta es muy independiente.

Para Ángel las actividades de cuidar la naturaleza y los animales resultaron muy divertidas, no conocía algunos animales como las vacas y los guajolotes pero le agradaron mucho.

Desarrollo linguiístico: Ángel demostró no tener problemas para expresarse, todo el tiempo hablaba y por cualquier cosa iniciaba la conversación. Cantar le parecía aburrido así que algunas veces no participaba en las actividades. Él ya usa oraciones, y aunque algunas palabras no las utiliza bien la gente logra entenderle.

Cuando llegaba a darle alguna instrucción al niño las entendía fácilmente y las hacía.
Desarrollo Psicosocial: durante las observaciones se pudo percibir que Gustavo es un niño muy tímido, le cuesta mucho trabajo establecer una relación con personas extrañas, todo el tiempo quería estar con su mamá. Nunca se le vio hacer un berrinche y no tenía ningún problema en compartir sus cosas con otros niños.

La relación con su madre es muy cercana y es muy notable, el niño aún está muy apegado a ella.

En la actividad de cuidar a la naturaleza Gustavo únicamente participó en la de regar plantas y recoger frutas por le tenía fobia a los animales, aunque no los conocía antes.
Desarrollo Cognitivo: En cuanto a noción de objeto y personas se pudo observar que Ángel reconoció con facilidad a sus familiares en las fotos y en algunas revistas, reconoció los roles como el doctor o el policía.

También sabía las causas de algunos efectos, como saber qué le pasa a un vaso si se avienta, o a una vela si se le sopla.

Su habilidad para clasificar no era muy buena sin embargo después de realizar algunos juegos con dulces y carritos aprendió a clasificar por tamaño y algunos colores.
Desarrollo linguístico: Gustavo tenía problemas para expresarse, la única persona con la que conversaba era con su madre. Durante las actividades de cantar él sólo bailaba y no cantaba. Él ya usa oraciones pero muy pequeñas, y la mayoría de las palabras que usa están mal pronunciadas. Muy pocas veces lo escuché hablar y la gente difícilmente le entiende.

Algunas veces cuando daba alguna instrucción él no la entendía.

Desarrollo Cognitivo: En cuanto a noción de objeto y personas se pudo observar que Gustavo reconoció con facilidad a sus padres en las fotos pero le costo trabajo reconocer a sus abuelitos o primos y en algunas revistas no reconoció los roles como el doctor y el policía.

También sabía las causas de algunos efectos, como saber que le pasa a un vaso si se avienta, o a una vela si se le sopla.

Su habilidad para clasificar no era muy buena y aún después de realizar algunos juegos con dulces y carritos le costó trabajo clasificar por tamaño o por colores.

\section{Codificación de los datos}

Área de Desarrollo Físico: A D F Área de Desarrollo Psicomotriz: A D PM Área de Desarrollo Psicosocial: A D PS
Área de Desarrollo Cognitivo: A D C Área de Desarrollo Lingüístico: A D L $A=$ Buen Desarrollo $B=$ Desarrollo Deficiente 


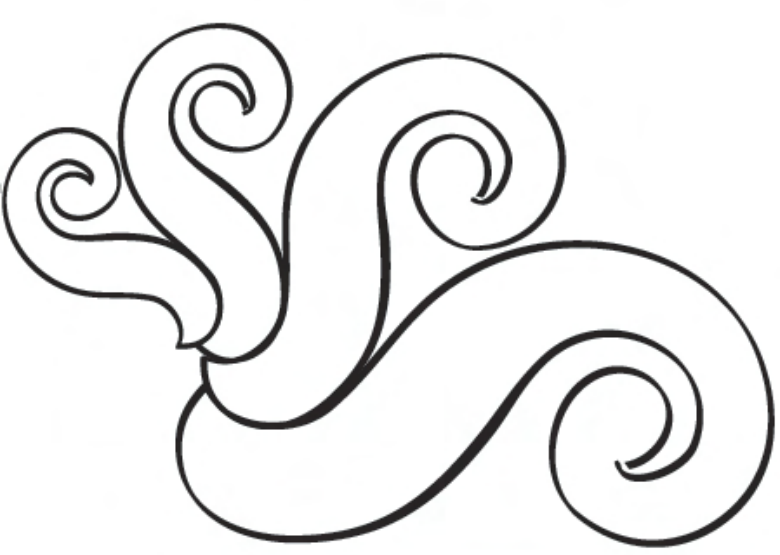

\begin{tabular}{|c|c|c|}
\hline & $\begin{array}{l}\text { Luis Ángel } \\
\text { Quezada Rubio }\end{array}$ & $\begin{array}{l}\text { Gustavo Alejandro } \\
\text { Ríos Reséndiz }\end{array}$ \\
\hline \begin{tabular}{|l|} 
AD F \\
1.peso y talla ideal \\
2.vitaminas \\
3.horarios comidas \\
4.número de comidas al día \\
5.comidas con familia \\
6.problemas para comer \\
7.inicio control de esfínteres \\
8.edad adecuada \\
9.forma de aprender el entrenamiento \\
\end{tabular} & $\begin{array}{l}\text { AD F } \\
\text { 1. a } \\
\text { 2. a } \\
\text { 3. b } \\
\text { 4. a } \\
\text { 5. a } \\
\text { 6. a } \\
\text { 7. a } \\
\text { 8. a } \\
\text { 9.a } \\
\end{array}$ & $\begin{array}{l}\text { ADF } \\
\text { 1. b } \\
\text { 2. b } \\
\text { 3. b } \\
\text { 4. a } \\
\text { 5. b } \\
\text { 6. b } \\
\text { 7. a } \\
\text { 8. b } \\
\text { 9. a } \\
\end{array}$ \\
\hline $\begin{array}{l}\text { D PM } \\
\text { 1.movimientos } \\
\text { 2.corre, sube escaleras } \\
\text { 3.toma lápiz, cuchara } \\
\text { 4.conoce partes del cuerpo } \\
\text { 5.conoce: derecha, izquierda, arriba } \\
\text { 6.camino a casa } \\
\text { 7.actividades artísticas } \\
\text { 8.imitación } \\
\text { 9.percepción de olores, sabores } \\
\end{array}$ & $\begin{array}{l}\text { AD PM } \\
\text { 1. a } \\
\text { 2. a } \\
\text { 3. a } \\
\text { 4. a } \\
\text { 5. a } \\
\text { 6. a } \\
\text { 7. a } \\
\text { 8. a } \\
\text { 9. a } \\
\end{array}$ & $\begin{array}{l}\text { AD PM } \\
\text { 1.a } \\
\text { 2. a } \\
\text { 3. b } \\
\text { 4. b } \\
\text { 5. b } \\
\text { 6. a } \\
\text { 7. a } \\
\text { 8. b } \\
\text { 9. b } \\
\end{array}$ \\
\hline \begin{tabular}{|l|} 
D PS \\
1.fácil relacionarse \\
2.convive con niños \\
3.autonomía \\
4.berrinches \\
5.compartir \\
6.egocentrismo \\
7.valores \\
8.cuidar naturaleza \\
9.no basura
\end{tabular} & $\begin{array}{l}\text { AD PS } \\
\text { 1. a } \\
\text { 2. a } \\
\text { 3. a } \\
\text { 4. a } \\
\text { 5. b } \\
\text { 6. a } \\
\text { 7. a } \\
\text { 8. a } \\
\text { 9. a }\end{array}$ & $\begin{array}{l}\text { AD PS } \\
\text { 1. b } \\
\text { 2. b } \\
\text { 3. b } \\
\text { 4. a } \\
\text { 5. a } \\
\text { 6. a } \\
\text { 7. a } \\
\text { 8. a } \\
\text { 9. a }\end{array}$ \\
\hline \begin{tabular}{|l|} 
ADC \\
1.uso de premios \\
2.uso de juguetes para construir, \\
rompecabezas \\
3.leer cuentos \\
4.conoce letra, números \\
5.animales, frutas \\
6.colores, tamaños \\
7.clasificar \\
8.reconocer familia \\
9.causa- efecto \\
\end{tabular} & $\begin{array}{l}\text { ADC } \\
\text { 1. a } \\
\text { 2. a } \\
\text { 3. a } \\
\text { 4. a } \\
\text { 5. a } \\
\text { 6. a } \\
\text { 7. b } \\
\text { 8. a } \\
\text { 9. a } \\
\end{array}$ & $\begin{array}{l}\text { ADC } \\
\text { 1.a } \\
\text { 2. a } \\
\text { 3. b } \\
\text { 4. b } \\
\text { 5. a } \\
\text { 6. b } \\
\text { 7. b } \\
\text { 8. b } \\
\text { 9. a } \\
\end{array}$ \\
\hline \begin{tabular}{|l|}
$\mathrm{AD} \mathrm{L}$ \\
1.usa señas \\
2.pronuncia bien \\
3.es corregido \\
4.es entendido \\
5.usa oraciones \\
6.comprende ordenes \\
7.lee cuentos \\
8.canta \\
9.platica \\
\end{tabular} & $\begin{array}{l}\text { ADL } \\
\text { 1. a } \\
\text { 2. a } \\
\text { 3. a } \\
\text { 4. a } \\
\text { 5. a } \\
\text { 6. a } \\
\text { 7. a } \\
\text { 8. a } \\
\text { 9. a }\end{array}$ & $\begin{array}{l}A D L \\
\text { 1. b } \\
\text { 2. b } \\
\text { 3. a } \\
\text { 4. b } \\
\text { 5. a } \\
\text { 6. a } \\
\text { 7. b } \\
\text { 8.a } \\
\text { 9. b } \\
\end{array}$ \\
\hline
\end{tabular}




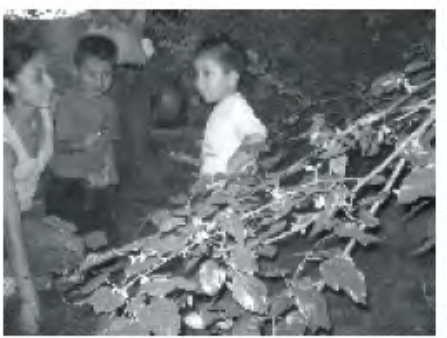

Ángel y Gustavo en el cuidado de las plantas.

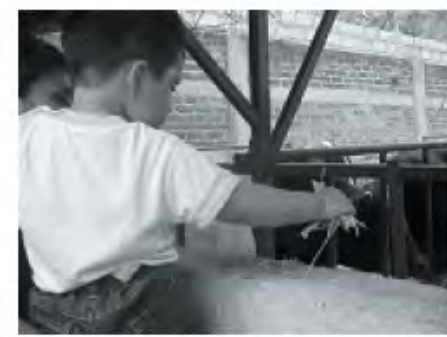

Ángel dando se comer a las vacas.

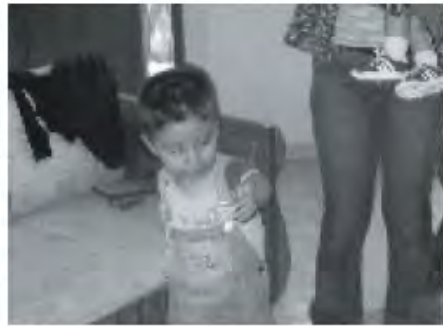

Gustavo bailando en la actividad de psicomotricidad.

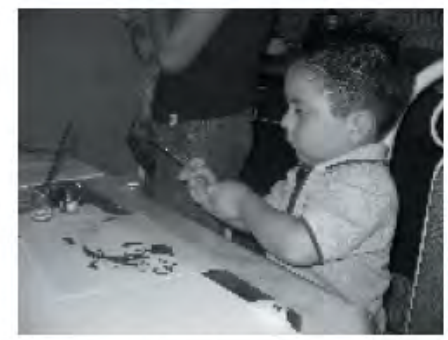

Ángel realizando actividad artística.

Gustavo intentando hacer bolitas de crepe

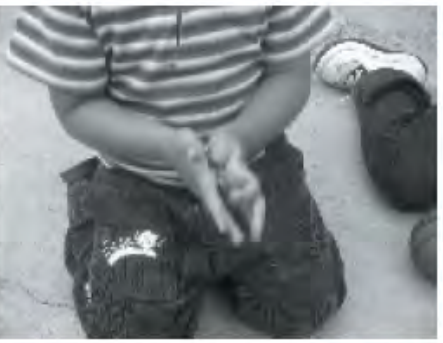

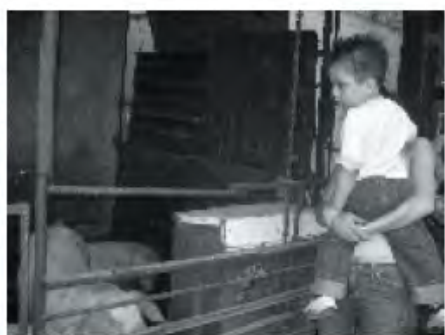

Ángel en la actividad de cuidar animales.

\section{Ángel dando de comer a los} borregos.
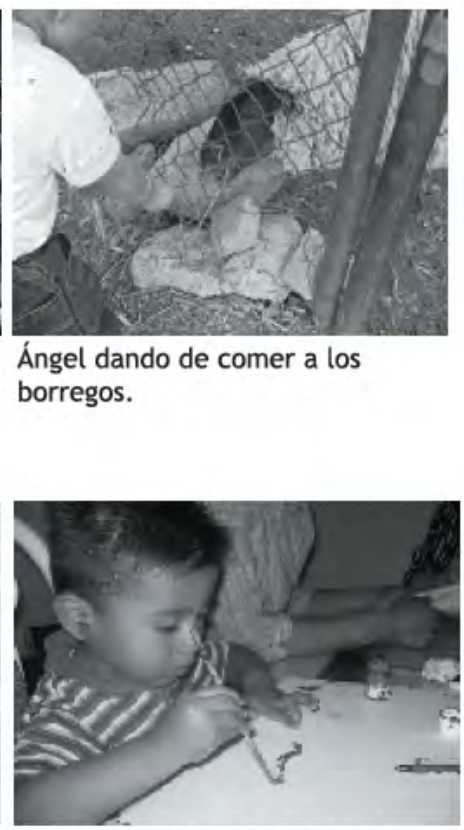

Gustavo realizando actividad artística.

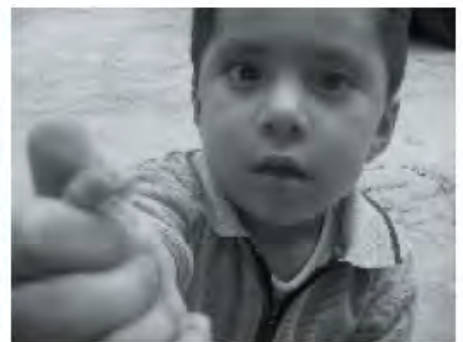

Ángel haciendo bolitas de crepe. 